\title{
Computational Modeling of Photoexcitation in DNA Single and Double Strands
}

\author{
You Lu, Zhenggang Lan, and Walter Thiel
}

\begin{abstract}
The photoexcitation of DNA strands triggers extremely complex photoinduced processes, which cannot be understood solely on the basis of the behavior of the nucleobase building blocks. Decisive factors in DNA oligomers and polymers include collective electronic effects, excitonic coupling, hydrogen-bonding interactions, local steric hindrance, charge transfer, and environmental and solvent effects. This chapter surveys recent theoretical and computational efforts to model real-world excited-state DNA strands using a variety of established and emerging theoretical methods. One central issue is the role of localized vs delocalized excitations and the extent to which they determine the nature and the temporal evolution of the initial photoexcitation in DNA strands.
\end{abstract}

Keywords Base pairing - Base stacking - Charge transfer - Delocalized state . DNA strand · Exciton · Hydrogen bond · Nonadiabatic dynamics · Photoexcitation · QM/MM

\footnotetext{
Y. $\mathrm{Lu}$

Scientific Computing and Modeling NV, Vrije Universiteit, De Boelelaan 1083, 1081HV, Amsterdam, The Netherlands

Z. Lan $(\bowtie)$

Key Laboratory of Biobased Materials, Qingdao Institute of Bioenergy and Bioprocess Technology, Chinese Academy of Sciences, 189 Songling Road, Qingdao 266101, Shandong, P. R. China

The Qingdao Key Laboratory of Solar Energy Utilization and Energy Storage Technology, QIBEBT-CAS, 189 Songling Road, Qingdao 266101, Shandong, P. R. China e-mail: lanzg@qibebt.ac.cn

W. Thiel (凶)

Max-Planck-Institut für Kohlenforschung, Kaiser-Wilhelm-Platz 1, 45470 Mülheim an der Ruhr, Germany

e-mail: thiel@kofo.mpg.de
} 


\section{Contents}

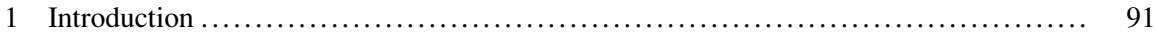



$2.1 \quad$ Excited-State Electronic Structure Methods ............................... 93

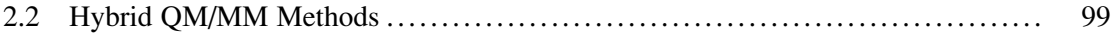

2.3 Nonadiabatic Dynamics .............................................. 99



3.1 Summary of Experimental Results ..................................... 101



3.3 Base Stacking in DNA Strands ...................................... 106

3.4 Base Pairing in DNA Strands ...................................... 109

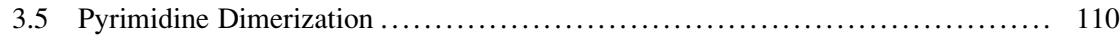

3.6 Other Helical Conformations and Modified Strands .......................... 113

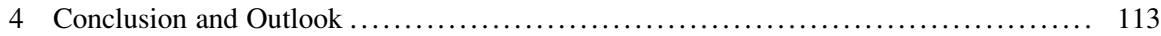

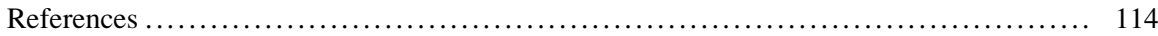

\section{Abbreviations}

A

$\mathrm{ADC}$

Ade

AM1

C

CASPT2

CASSCF

$\mathrm{CC}$

$\mathrm{CC} 2$

CCSD

CI

CIS

CISD

CMP

CPD

CT

Cyt

dA

dAdo

$\mathrm{dC}$

DFT

dG

DNA

dT

dThd

FAD

G

GMP
Adenine derivatives

Algebraic diagrammatic construction

9H-Adenine

Austin model 1

Cytosine derivatives

Complete active space second-order perturbation theory

Complete active space self-consistent field

Coupled cluster

Second-order coupled cluster

Coupled cluster singles and doubles

Configuration interaction

Configuration interaction singles

Configuration interaction singles and doubles

Cytidine monophosphate

Cyclobutane pyrimidine dimer

Charge transfer

Cytosine

Deoxyadenosine monophosphate (or dAMP)

Deoxyadenosine

Deoxycytidine monophosphate (or dCMP)

Density functional theory

Deoxyguanosine monophosphate (or dGMP)

Deoxyribonucleic acid

Deoxythymidine monophosphate (or dGMP)

Deoxythymidine

Flavin adenine dinucleotide

Guanine derivatives

Guanosine monophosphate 


$\begin{array}{ll}\text { Gua } & \text { 9H-Guanine } \\ \text { HF } & \text { Hartree-Fock } \\ \text { KS } & \text { Kohn-Sham } \\ \text { LIIC } & \text { Linear interpolation in internal coordinates } \\ \text { LRC-TDDFT } & \text { Long-range-corrected time-dependent density functional theory } \\ \text { LR-TDDFT } & \text { Linear response time-dependent density functional theory } \\ \mathrm{m}^{1} \mathrm{~T} & \text { 1-Methylthymine } \\ \mathrm{m}^{9} \mathrm{~A} & \text { 9-Methyladenine } \\ \text { MCSCF } & \text { Multi-configurational self-consistent field } \\ \text { MD } & \text { Molecular dynamics } \\ \text { MNDO } & \text { Modified neglect of diatomic overlap } \\ \text { MO } & \text { Molecular orbital } \\ \text { MP2 } & \text { Second-order Møller-Plesset perturbation } \\ \text { MRCI } & \text { Multi-reference configuration interaction } \\ \text { NDDO } & \text { Neglect of diatomic differential overlap } \\ \text { OM2 } & \text { Orthogonalization model 2 } \\ \text { PCM } & \text { Polarizable continuum model } \\ \text { PES } & \text { Potential energy surface } \\ \text { PM3 } & \text { Parameterized model 3 } \\ \text { QM/MM } & \text { Quantum mechanics/molecular mechanics } \\ \text { RNA } & \text { Ribonucleic acid } \\ \text { RPA } & \text { Random phase approximation } \\ \text { T } & \text { Thymine derivatives } \\ \text { TDA } & \text { Tamm-Dancoff approximation } \\ \text { TDDFT } & \text { Time-dependent density functional theory } \\ \text { TDHF } & \text { Time-dependent Hartree-Fock } \\ \text { Thy } & \text { Thymine } \\ \text { TSH } & \text { Trajectory surface hopping } \\ \text { UV } & \text { Ultraviolet } \\ \text { ZDO } & \text { Zero overlap differential } \\ \text { ZINDO } & \text { Zerner's intermediate neglect of differential overlap } \\ \text { ZINDO/S } & \text { Zerner's intermediate neglect of differential overlap for spectra } \\ & \end{array}$

\section{Introduction}

In the fields of photophysics, photochemistry, and photobiology, one essential goal is to understand the photoinduced reactions of deoxyribonucleic acid (DNA) and ribonucleic acid (RNA) that are crucial for the photostability of the genetic material. In the past decades, thanks to the rapid development of spectroscopic techniques, numerous advanced experiments have provided detailed information on DNA excited-state processes [1-11]. Even so, it is rather difficult for experimental work alone to identify the roles of the many different mechanisms that are entangled with each other during DNA photoreactions. Therefore, theoretical studies have become 
valuable as guides and supplements to experimental studies [12-14]. However, the theoretical treatment of complex excited-state DNA systems is clearly still very challenging $[12,14,15]$.

All photoinduced processes of DNA start with an initial photoexcitation. The building blocks of DNA and RNA - adenine (A), thymine (T), guanine $(\mathrm{G})$, cytosine $(\mathrm{C})$, and uracil $(\mathrm{U})^{1}[16,17]$ - contain five- and/or six-membered aromatic rings, which show strong absorption in the ultraviolet (UV) between 4-6 eV [1, 18, 19]. The absorption (and emission) spectra of DNA strands are not simply a superposition of the corresponding spectra of the individual nucleobases (or nucleosides/ nucleotides). Instead, excitations on individual bases may couple to each other such that the overall excitation becomes delocalized over multiple bases [4-6, 9, 10]. If this is the case, an excimer/exciplex (an excited-state dimer/excited-state complex) will be formed [5], which is called a Frenkel exciton if the promoted electron is still tightly bound to the generated "hole" through Coulomb interactions [4, 5, 10, 20]. The formation mechanism of delocalized states in DNA strands is still debated, especially with regard to the size of the delocalized domain [5].

Studying DNA excited-state dynamics is even more challenging due to the existence of many possible reaction channels. Time-resolved spectroscopic experiments show that the UV absorption of DNA is followed by an ultrafast decay of the excited states [5, 21]. This indicates the existence of nonadiabatic processes, i.e., transitions from one electronic state to another through efficient nonradiative internal-conversion channels that allow the system to repopulate the electronic ground state $[2,5]$. Such processes have drawn much recent interest, since they are believed to be dominant in many excited-state phenomena, such as the internal conversion of nucleobase monomers, hydrogen transfer between adjacent paired bases, and the nonradiative decay of stacked bases through delocalized pathways [5]. Proper modeling of such dynamical processes requires descriptions that take into account the breakdown of the Born-Oppenheimer approximation and the coupling of electronic and nuclear motion during internal conversion [22, 23].

Nonadiabatic processes are capable of dissipating the excess energy brought by photons before further photochemical reactions take place. This prevents organisms from being damaged by photoreactions and thus provides photostability [24]. It is conceivable that photostability is an outcome of natural selection during evolution [25]. In organisms, more than $99.9 \%$ of photon energy is dissipated through photoprotection mechanisms [26], with the remainder $(<0.1 \%)$ being responsible for sunburn and some skin cancers [27, 28]. In the latter case, photolesion occurs as DNA strands undergo complicated photochemical reactions. Dimerization of two stacked pyrimidines is commonly perceived as the mechanism of photolesion [5, 29]. However, on the theoretical side, there are still open points in the modeling of pyrimidine dimerization that need to be clarified [5], since it is difficult to set up

\footnotetext{
${ }^{1}$ We use the IUB 1984 one-letter abbreviations [16] for the associated DNA strand building blocks, while we specify the variants of nucleobase, nucleoside, or nucleotide with the IUPACIUB 1970 three-letter abbreviations [17] (throughout the chapter unless otherwise stated).
} 
reasonable models for the potential influence of the photoinactive sugar-phosphate backbones and the biological/solvent environments while balancing computational accuracy and efficiency [30, 31].

Much recent research has been devoted to the mechanisms of the various photoinduced processes that occur in DNA strands after UV excitation [5, 8, 32-37]. In this chapter, we outline recent progress in computational studies on the photoexcitation of DNA strands. Given the limited space, we do not aim for a comprehensive account of all published work, but rather for a general overview. We highlight the most important experimental advances in this field only briefly, since they have been presented in recent reviews [2-11] and in other chapters of this book. Likewise, we cover the excited-state features of small DNA units, such as single nucleobases and hydrogen-bonded base pairs, only to the extent needed for the discussion of the DNA strands, without going into much detail. This chapter is structured as follows. Section 2 introduces the theoretical models and computational techniques often applied to excited-state DNA systems. Section 3 first summarizes the experimental results (Sect. 3.1) and then reviews theoretical studies on DNA excited states (Sect. 3.2) at different stages of modeling - from isolated nucleobases via single nucleobases in DNA strands and stacked nucleobases to solvated DNA single and double strands. In Sects. 3.3 and 3.4 we discuss the effects of base stacking and pairing on the photoinduced processes of DNA strands, as well as the influence of the DNA biological/solvent environment and the formation of excitons and excimers/exciplexes. Finally, we address the photodamage caused by dimerization (Sect. 3.5) and the photoexcitation of modified and other helical conformations of DNA strands (Sect. 3.6).

\section{Theoretical Background}

\subsection{Excited-State Electronic Structure Methods}

The past few decades have witnessed the development of a hierarchy of quantumchemical methods that can be used to investigate the structures and properties of molecules and solids [38,39]. Nowadays, properties and reactions in the electronic ground state can be studied routinely by computation. High-level ab initio methods, such as coupled cluster theory [40] and Møller-Plesset perturbation theory [41], give accurate predictions for ground-state properties. Because of its favorable costperformance ratio, density functional theory (DFT) is used widely and successfully in studies of chemical reactions [42], both in organic and transition metal chemistry. Moreover, there are fast semiempirical approaches for treating large systems [43, 44]. One of the central tasks in this field is to develop efficient high-level correlated methods to deal with large systems without losing much accuracy $[38,39]$.

Concerning excited states, electronic-structure calculations provide information on various kinds of spectra (including absorption, emission, electronic energy loss, 
and circular dichroism spectra), on excited-state potential energy surfaces (PESs) and reaction pathways, and on the geometries of excited-state minima, conical intersections, and intermediates [14, 15, 45-49]. Generally speaking, the modeling is more demanding for excited states than for the ground state, and many different approaches are in use $[14,15]$. However, unlike in the case of the ground state, there is no "standard" approach to excited-state electronic-structure problems in general. The existing excited-state electronic-structure methods all have their merits and shortcomings - with regard to accuracy, general applicability, and computational demand [50-55]. One should thus carefully examine the suitability of the available methods before making a specific choice for a given application [14, 15]. In the following, we give a brief overview of some of the mainstream theories for calculating the electronic structure of excited states.

\subsubsection{Configuration Interaction}

The configuration interaction (CI) ansatz [50, 56, 57] describes the electronic wavefunction as a linear combination of configuration state functions (in the simplest case: Slater determinants). The CI eigenvalues and eigenvectors are determined by a variational calculation [56, 57]. In the standard single-reference CI treatment, all excited configurations are generated from just one reference configuration. In most cases, the ground-state Slater determinant obtained from Hartree-Fock (HF) theory is taken as the reference, and the excited configurations are derived by exciting electrons from the occupied HF molecular orbitals (MOs) to the virtual MOs. Inclusion of all possible excited configurations leads to full CI (FCI) treatment, which yields the exact results for the given basis set. However, even for small compounds, FCI is extremely expensive [56, 57]. Thus, in practice, approximations are adopted to reduce the number of configurations in the CI expansion, typically by truncating at a certain excitation level. Inclusion of only single or only single and double excitations results in the popular CIS and CISD methods, respectively. The efficient CIS approach can easily be applied to mediumsized systems such as the DNA nucleobases [58-61]. CIS will give a qualitatively reasonable description if the problem under study happens to involve just single excitations. Still, the accuracy of CIS is often unsatisfactory, as there can be errors in the computed vertical excitation energies of more than $1.5 \mathrm{eV}$ in some cases [14]. The deviations may become even larger when doubly excited or charge-transfer excited states are involved [62].

\subsubsection{Coupled Cluster Theory}

Among the single-reference methods, coupled cluster (CC) theory provides some of the most accurate models for excited states [51, 53, 54]. They are size-consistent and size-extensive by design. The coupled-cluster expansion [40] automatically includes the contributions of many higher-order excitations (i.e., those that can be 
constructed from the lower-order terms via the exponential cluster ansatz). Most widely used is the coupled cluster method with single and double excitations (CCSD). Inclusion of a perturbational estimate of the contributions from the triple excitations leads to the CCSD(T) method that is currently considered as the "gold standard" for ground-state calculations [63]. For electronically excited states, approximate $\mathrm{CC}$ treatments can be formulated in the framework of linear response theory, for example CC2 (second order) or CC3 (third order) [64]. CC2 is quite efficient and fairly accurate for excited states that are dominated by single excitations $[51,54]$. An alternative is the equation-of-motion coupled cluster (EOM-CC) method [65-68] which has been implemented at the EOM-CCSD and higher levels, also on massively parallel computers [69]. The EOM-CC approaches are computationally very demanding, but also very accurate. In benchmarks by Szalay and coworkers, they were shown to be capable of describing excited-state DNA building blocks most accurately [68, 70-72]. CC-based methods have been applied successfully to study the excited states of DNA nucleobase/strand systems, for example in [67, 73-76].

\subsubsection{Multi-configuration and Multi-reference Treatments}

Sometimes the HF determinant does not provide a qualitatively adequate zero-order description of the electronic structure, for example in quasi-degenerate states as encountered near conical intersections. Such situations can be handled by the multi-configurational self-consistent-field (MCSCF) method. In this ansatz, the wavefunction is expanded in terms of a set of predefined configurations, and both the MO and CI coefficients are optimized [77-81]. The MCSCF theory is thus fully variational with respect to the MO and CI vectors. A systematic approach is to define an active space including a limited number of MOs and to perform an FCI treatment within the active space - this is the complete active space self-consistent-field (CASSCF) method [77, 80]. A simplified variant is the restricted active space selfconsistent-field (RASSCF) method [82,83], in which the active space is partitioned and CI excitations are truncated for certain parts of the active space. CASSCF and RASSCF can describe quasi-degenerate electronic states in a qualitatively correct manner, and they are therefore well suited for exploring the topology of excited-state potential surfaces. Being popular tools in theoretical studies of excited states, they have been used for constructing nucleobase photoreaction paths and for simulating nucleobase photodynamics, for example, in [73, 84-87]. However, because of limitations in the size of the active space, CASSCF misses much of the dynamic electron correlation, which may cause large errors in the computed excitation energies. A remedy is to apply second-order perturbation theory on top of CASSCF $[88,89]$. The resulting CASPT2 treatment generally gives excellent excitation energies [51, 55, 88, 89] for the valence excited states of organic molecules. The computational cost of the CAS methods grows dramatically with the active space size. In practice, active spaces with 14-18 orbitals/electrons can typically be handled with currently available computational resources, which are just about sufficient for 
an appropriate description of nucleobases and base pairs. The proper choice of the active space is crucial in CAS methods, because missing relevant orbitals may lead to unsafe results, even for vertical excitation energies [51, 55]. An alternative to CASPT2 is to perform multi-reference configuration interaction (MRCI) calculations based on CASSCF orbitals [81]. For example, selected CASSCF solutions can be used as references on which the CI expansion is built, typically by considering single and double excitations. In this manner, one may construct small CI expansions that yield reasonable results with affordable computational cost [81]

\subsubsection{Semiempirical Methods}

In the ab initio Hartree-Fock approach, the construction of the Fock matrix requires evaluation of a large number of multicenter two-electron integrals over the atomic orbitals. This step can be rather time-consuming for large systems. In semiempirical methods, many of these integrals are neglected, and the remaining ones are usually represented by expressions containing parameters that are adjusted against experimental reference data. There are several levels of approximation that result in different semiempirical models [43, 44]. Popular semiempirical MO methods include AM1 (Austin model 1) [90], PMx (parameterized models, $x=3-7$ ) [91-96], and OMx (orthogonalization models, $x=1-3$ ) [97-101]. Any type of semiempirical Hamiltonian can be integrated into CI approaches to describe excited states. Early attempts were the development of ZINDO/S [102, 103] and AM1/CI [104]. It was pointed out that ZINDO/S outperforms other semiempirical methods in the description of the DNA charge-transfer electronic coupling [105]. The $\mathrm{AM} 1 / \mathrm{CI}$ and PM3/CI methods were recently shown to be capable of modeling semiclassical nonadiabatic dynamics of DNA fragments [106, 107].

Most semiempirical models rely on the zero differential overlap (ZDO) approximation and thus tend to fail in properly predicting MO energy gaps [100] and excitation energies. Carrying out a targeted reparameterization can partly make up for this deficiency - for example, ZINDO/S was especially parameterized to reproduce electronic spectra [108]. An alternative is to include orthogonalization corrections into the semiempirical Fock matrix as done in the OM $x$ methods. This leads to an asymmetric splitting of bonding and antibonding orbitals, with the latter being destabilized more than the former are stabilized (as in the ab initio case and hence superior to the symmetric splitting in standard ZDO-based methods). The $\mathrm{OM} x$ MOs thus provide a reasonable starting point for an MRCI treatment of electronically excited states. Conceptually, dynamic electron correlation is effectively incorporated in the semiempirical Hamiltonian, and it is thus generally sufficient to perform OM $x$ /MRCI calculations with a small (minimum) number of reference configurations and a rather small active space (typically including only single and double excitations). Benchmark calculations show that the OM2/MRCI approach gives rather reliable results for the excited states of many organic molecules [109]. For example, the overall mean absolute deviation of (singlet and 
triplet) vertical excitation energies is about $0.4-0.5 \mathrm{eV}$ [109]. OM2/MRCI was successfully employed in a series of studies on both the static excited-state properties and the nonadiabatic dynamics of DNA base/strand systems [110-116].

\subsubsection{Density Functional Theory}

Density functional theory (DFT) is currently the workhorse for most ground-state calculations, thanks to its reliability and high efficiency [42]. Its time-dependent version (TDDFT) [50, 117] is designed to compute excited-state properties. In most cases, TDDFT calculations evaluate the linear response (LR) of the time-dependent Kohn-Sham (KS) density to the perturbing external potential. This LR-TDDFT approach has become the standard TDDFT implementation [50, 117]. Since it is computationally efficient and appears like a "black-box" method, TDDFT is currently the most popular single-determinant method for treating excited states [117]. However, it should be applied with caution, because it is not a genuine "black-box" method and has prominent limitations $[14,50]$. TDDFT generally describes valence excited states quite well, with absolute mean deviations of about $0.3-0.5 \mathrm{eV}$ for excitation energies (compared with accurate ab initio results) [52]; however, when charge-transfer excitations are involved, TDDFT with standard functionals is erratic and yields severely underestimated excitation energies [14, 50, 118]. Moreover, doubly-excited states cannot be handled unless one resorts to special treatments [119]. Range-separated hybrid functionals were developed to overcome the charge-transfer problems, by introducing different weights of HF exchange for short-range and long-range interactions. Validations of long-range-corrected (LRC) TDDFT methods [120] for charge-transfer states of $\pi$-stacked adenines showed that their performance can be tuned well by introducing an adjustable length-scale parameter [60, 121]. In comparisons [122] of three recent LRC functionals, namely BNL [123, 124], CAM-B3LYP [125], and LC-PBE0 [126, 127], it was found that only CAM-B3LYP gave reasonable energies for the interbase charge-transfer excited states of the hydrogen-bonded Watson-Crick A.T and G.C base pairs. There are also indications that the meta-hybrid M06-HF [128] and M06-2X [129] functionals may be adequate to treat the photoexcitation of nucleobase monomers and oligomers [130]. However, in a systematic excited-state dynamics study of $9 \mathrm{H}$-adenine (Ade), the experimentally observed ultrafast decay was not reproduced in TDDFT-based surface hopping simulations with any of the six tested functionals (PBE, B3LYP, PBE0, CAM-B3LYP, BHLYP, and M06-HF) whereas reasonable decay times were obtained at the ab initio MRCIS and the semiempirical OM2/MRCI levels [131]. TDDFT is widely applied to construct delocalized exciton-type Hamiltonians for DNA strands consisting of stacked nucleobases (see Sect. 2.1.7).

As a single-reference method, canonical TDDFT encounters severe difficulties around conical intersections. The Tamm-Dancoff approximation (TDA) [50] is presumed to alleviate the problems associated with nearly degenerate states [132-134], 
but its performance still needs to be examined carefully. An alternative promising approach to handle such situations is provided by multi-reference DFT-based methods such as DFT/MRCI [135].

\subsubsection{Polarization Propagator Methods}

Response theory can be applied not only to KS-DFT but also to other theoretical schemes. In this framework, one computes the frequency-dependent polarizability (i.e., the response to the incoming light) and determines the excitation energies from the poles of this function. This approach is called polarization propagator [136] because of its relation to the many-body Green's function propagator theory. Popular response methods for excited-state calculations are time-dependent HF (TDHF) theory and the random phase approximation (RPA), with the latter providing results of similar quality as CIS [50]. A perturbative expansion [137] can be applied to the polarization propagator using the algebraic diagrammatic construction (ADC) [138]. Expansion up to second and third order leads to the ADC(2) and $\mathrm{ADC}(3)$ methods, respectively. Loosely speaking, $\mathrm{ADC}(2)$ can be considered as an MP2 variant for excited states. It often provides excellent accuracy, particularly for charge-transfer states that are problematic in TDDFT. ADC methods have been applied successfully to simulate a DNA double-stranded system [76] (see Sect. 3.3).

\subsubsection{Excitons}

The electronic transition triggered by photoexcitation may lead to charge separation between the electron being excited $\left(\mathrm{e}^{-}\right)$and the remaining hole $\left(\mathrm{h}^{+}\right)$. The term "exciton" denotes a bound state that is supported by the Coulomb attraction between this electron and the hole. This concept is borrowed from solid-state physics: when the $\mathrm{e}^{-} / \mathrm{h}^{+}$pair is separated by a sufficiently large distance, there is a completely delocalized Wannier-Mott exciton that is often encountered in metals and semiconductors [139]; when the distance is not large enough, a Frenkel exciton [20] is formed with a relatively localized excitation that may, however, still be delocalized over several chromophore units. Excitons may thus be formed by or after photoexcitation in complex systems with multiple similar chromophores, such as for instance in DNA strands [5].

In quantum chemistry, the extent of localization/delocalization of a Frenkel exciton can be assessed through the coupling between the excitations on different individual chromophores. As an example, we briefly outline a typical procedure used for constructing an excitonic model of DNA strands [140, 141]. First, a ground-state molecular dynamics (MD) simulation was run to get a few snapshots with different conformations of DNA strands. For each of them, the low-lying excited states of the individual bases were then calculated at the quantum level, including the electrostatic interactions with the other bases in the strand and with 
the solvent environment, which defined the diagonal terms of the excitonic Hamiltonian. The off-diagonal terms (i.e., the electronic couplings between different chromophore units) were evaluated from the dipole-dipole interactions. The electronic states of the DNA strands were then obtained by diagonalizing the excitonic Hamiltonian. The energies, couplings, and eigenstates of the chromophore units showed some fluctuation among the MD snapshots.

\subsection{Hybrid QM/MM Methods}

The theoretical description of the excited states of solvated DNA bases/oligomers/ polymers (with thousands of atoms) is challenging because of the high computational demands of the electronic-structure calculations. Fortunately, photoinduced processes usually take place within a relatively small part of the whole system, and the remaining thousands of atoms have only an indirect influence, mainly through steric and electrostatic interactions. In such a situation, it is reasonable to apply the hybrid quantum mechanics/molecular mechanics (QM/MM) method [142, 143] which divides the system into (at least) two subdomains: the QM region is the photoactive part that is treated at a suitable level of quantum mechanics; the MM region, containing the remaining part of the whole system including solvent, is mimicked by a molecular mechanics method (normally an additive force field). The electrostatic interactions between the QM and MM parts can be treated at different levels of approximation. As the name suggests, mechanical embedding completely neglects polarization effects between the QM and MM regions so that the MM environment only affords steric effects. By contrast, electronic embedding considers the QM region as being immersed in a background of MM point charges (effective force-field charges), which leads to electronic QM polarization in response to the MM environment. Electronic QM/MM embedding was shown to be indispensable for correctly representing excited-state DNA systems, as it strikingly modulates the excited-state dynamics [76, 114, 115, 144].

Some QM-only investigations on DNA excited states have employed implicit solvent models [145, 146], e.g., the polarizable continuum model (PCM) [147-158]. Since these models do not consider the explicit atomic surrounding of the investigated DNA chromophores, they simplify the complex biomolecular environment in DNA by treating it as a homogeneous solvent with an effective dielectricity constant.

\section{$2.3 \quad$ Nonadiabatic Dynamics}

Compared with the ground state, the PES topology is usually far more complicated in excited states. Photoexcitation may trigger a number of complex photoinduced processes including reactions on a single excited-state PES as well as transitions between different electronic states, the PESs of which may approach or even cross each other. One type of surface crossing is a conical intersection [45, 47-49] 
between two electronic states with the same multiplicity. In the vicinity of conical intersections, strong interstate couplings (nonadiabatic vibronic couplings) induce ultrafast transitions between the states. The theoretical description of such internal conversion processes must go beyond the Born-Oppenheimer approximation and account for the coupled electron-nuclear motion [23]. A second type of crossing is due to the spin-orbit coupling between states of different multiplicities; such intersystem crossings may also be involved in some photoprocesses of DNA [159-163], as discussed, for example, in [5]. However, internal conversion is generally considered to be the mechanism that dominates the photoinduced processes in DNA systems [5, 18, 19].

For a detailed understanding of DNA photoreactions, it is essential to run nonadiabatic excited-state dynamics to determine the branching ratios of possible reaction channels, the lifetimes of excited-state species, and time-resolved spectra. This is challenging given both the size and complexity of DNA and the need for a self-consistent treatment of the electronic and nuclear degrees of freedom. Among the various available dynamics methods [22, 48, 49, 164-166], the trajectory surface hopping (TSH) approach is one of the most popular [15]. TSH propagates the nuclear motion along a classical trajectory on a single adiabatic PES, while computing the electronic wavefunction at each step on the fly. Nonadiabatic transitions are modeled as instantaneous hops between different adiabatic PESs. There are different approaches to determine the hopping probability, with the fewest-switches algorithm [167] being most widely used. Due to its simplicity, TSH can be easily performed at different theoretical levels, both QM-only and QM/MM $[14,15]$. In the TSH framework, the photodynamic behavior remains fully governed by the PESs, but pre-construction of high-dimensional PESs is avoided. TSH is commonly considered as a most practical tool for efficient nonadiabatic dynamics simulations in large systems like DNA strands. Successful TSH studies on DNA photodynamics will be presented in Sect. 3.

Other nonadiabatic dynamics methods include multi-configuration time-dependent Hartree [164, 168], ab initio multiple spawning [165, 166], mean-field Ehrenfest dynamics [169], coherent switching with decay of mixing [170], and quantumclassical Liouville [169] approaches. Some of these are very expensive and not yet applicable to DNA systems, while others have been employed to study DNA photochemistry. For example, a recently developed method called semiclassical electron-radiation-ion dynamics, a kind of real-time electrodynamics starting from the Ehrenfest theorem, was reported to give reasonable results for excited-state DNA bases [171].

\section{Photoexcitation of DNA Strands}

Various theoretical approaches (see the preceding section) have been applied to model virtually every aspect of DNA photoexcitation, including energetics [122, 172], base-pairing and electronic coupling [173], damage and repair reactions 
$[174,175], \pi$-stacking and excited-state delocalization (charge transfer, excimers/ exciplexes, and excitons) [140, 176-178], and excited-state dynamics [144]. In this section we overview recent results of computational efforts directed toward understanding the photoexcitation in DNA strands. None of the currently available theoretical approaches is yet quantitatively reliable in modeling a system as large as solvated DNA strands. Simulation of the excited-state dynamics in the condensed phase is especially challenging because of the need to describe realistically both the electronic structure of all relevant electronic states under the influence of the environment and the dynamics of the entire system. A single nucleobase embedded in DNA strands (Sect. 3.2) serves as a starting point to approach real DNA systems. Stacked base oligomers (Sect. 3.3) and base pairs (Sect. 3.4) have been studied as simple models of DNA strands. The mechanisms of DNA photodamage are discussed in Sect. 3.5. The photoexcitation of other types of DNA strands is reviewed briefly in Sect. 3.6.

\subsection{Summary of Experimental Results}

Numerous experimental studies employing several time-resolved spectroscopic techniques have been reported on solvated DNA models in the past decade. The simplest models in the condensed phase are single nucleobases (or single nucleosides/nucleotides), e.g., $9 H$-adenine [or 9-methyladenine $\left(\mathrm{m}^{9} \mathrm{~A}\right) /$ deoxyadenosine (dAdo)], which were found to exhibit decay time constants of 180-670 fs in water, slightly shorter than in the gas phase [113]. Regarding the more complicated photophysics and photochemistry of DNA, the spectroscopists have reported multiexponential decay behavior with time constants ranging from hundreds of femtoseconds to hundreds of picoseconds [5]. To rationalize the much longer components compared to isolated (gas-phase or solvated) nucleobases, it was suggested that the photodynamics in DNA may be composed of multiple decay channels involving localized and/or delocalized states and processes. A variety of decay models have been proposed to explain the puzzling observations. Comprehensive surveys of the massive amounts of experimental spectroscopic results are given in the reviews and perspectives about DNA excitation by Kohler, Markovitsi, and others [3, 5, 7, 9-11, 179]. The A/T and $\mathrm{G} / \mathrm{C}$ strands show generally similar behavior upon photoexcitation, so we take the $\mathrm{A} / \mathrm{T}$ strands as an example and highlight the primary hypotheses as follows:

- The Kohler group $[5,7,180,181]$ investigated $(\mathrm{dA})_{18}$ and $(\mathrm{dA})_{18} \cdot(\mathrm{dT})_{18}$ (where we use a middle dot "." to denote the hydrogen-bonded base paring from here on; dA is deoxyadenosine monophosphate and $\mathrm{dT}$ is deoxythymidine monophosphate, as depicted in Fig. 1). They concluded that singlet excited states of single or poorly stacked bases relax to the hot ground state by ultrafast internal conversion within $1 \mathrm{ps}$, while initial excitons delocalized over several bases rapidly (sub-picosecond) evolve into localized excimers or charge-transfer (CT) states that survive longer

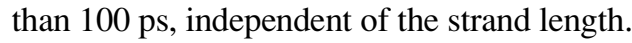


Fig. 1 Chemical structures and Watson-Crick base pairs of deoxyadenosine monophosphate (dA or dAMP), deoxythymidine monophosphate (dT or dTMP), deoxyguanosine monophosphate ( $\mathrm{dG}$ or dGMP), and deoxycytidine monophosphate ( $\mathrm{dC}$ or $\mathrm{dCMP}$ ) that occur as building blocks in DNA strands
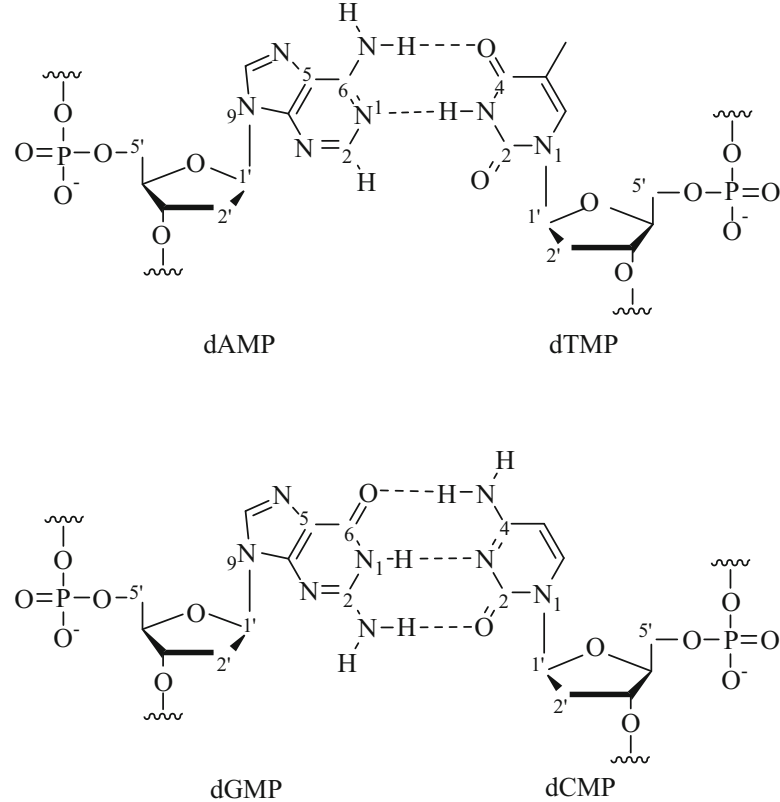

- The Fiebig group $[182,183]$ studied $(\mathrm{dA})_{2-18}$ and $(\mathrm{dA})_{12 / 18} \cdot(\mathrm{dT})_{12 / 18}$. Their fits gave a monoexponential time constant of $\sim 8 \mathrm{ps,} \mathrm{which} \mathrm{was} \mathrm{ascribed} \mathrm{to} \mathrm{electron-}$ ically relaxed excitons that were initially formed upon UV absorption. They conjectured an excitonic delocalization over at least three bases.

- Markovitsi and coworkers [4, 9, 184-186] measured $(\mathrm{dA})_{20},(\mathrm{dA})_{20} \cdot(\mathrm{dT})_{20}$, and double-stranded polymers $(\mathrm{dA})_{n} \cdot(\mathrm{dT})_{n}$. They also detected multiexponential decay components of $0.3-0.85 \mathrm{ps}, 1.6-3.9 \mathrm{ps}$, and up to $187 \mathrm{ps}$. They interpreted their findings as Frenkel and/or CT excitons [20, 187, 188] extending over several bases, which were proposed to give rise to the longer components after ultrafast $(<100 \mathrm{fs})$ intraband scattering. They suggested that the decay of ${ }^{1} \pi \rightarrow \pi^{*}$ and/or ${ }^{1} \mathrm{n} \rightarrow \pi^{*}$ states of unstacked thymine/adenine bases corresponds to the faster components.

- Markovitsi and coworkers [154, 189] recently proposed a general diagram for the excited-state processes in natural calf thymus DNA: the optically bright excitonic states first decay to charge-transfer and/or charge-separated states (the distinction being whether donor $\mathrm{D}^{+}$and acceptor $\mathrm{A}^{-}$are close to or far away from each other); ${ }^{1} \pi \rightarrow \pi^{*}$ states that cause the delayed fluorescent emission are then accessed through charge recombination, intraband scattering, and excitonic localization, while the ground state is primarily repopulated by charge recombination.

- Using a triexponential decay function, Schwalb and Temps [190] reported similar fitting results with time constants of $0.52-0.63,2.6-5.8$, and 16.2$97.0 \mathrm{ps}$ for their up-conversion experiments on $(\mathrm{dA})_{20}$ and $(\mathrm{dA})_{20} \cdot(\mathrm{dT})_{20}$. 
- Phillips and coworkers [191] proposed a decay mechanism of $(\mathrm{dA})_{20}$, in which all components originate from monomeric adenine excitations, which then embark on different decay paths including radiationless internal conversion ( $\sim 0.39 \mathrm{ps})$ and the formation of two excimers ( 4.3 and $\sim 182 \mathrm{ps})$.

Moreover, a series of circular dichroism experiments [37, 192, 193] showed that the initial excitation in DNA homopolymers (adenine, thymine, and cytosine) generates excitons limited to only two bases, while the exciton extends over more bases in RNA homopolymers (adenine). It is noteworthy that the simple dinucleotide $2^{\prime}$-deoxyadenylyl $\left(3^{\prime} \rightarrow 5^{\prime}\right)$-thymidine $(\mathrm{dApdT})$, which easily becomes unstacked in aqueous solution, also exhibits long-lived ( $\sim 5$ and $\sim 75$ ps) excitedstate dynamics [194]. This implies that $\pi$-stacking of multiple nucleobases may not necessarily be the only origin of the long-lived species in DNA strands. Hence, although a number of interpretations have emerged to rationalize the experimental observations, there is still a long way to go before arriving at a consensus on all aspects of DNA photoexcitation. Controversial issues include the localized and/or delocalized character of the excited states and the effects of the environment (solvent and DNA backbone), which call for computational studies.

\subsection{Single Bases in DNA Strands}

The enigma of DNA photochemistry has aroused much interest on the theoretical side. There have been many theoretical efforts to establish sound models for DNA photochemistry and to explain the experimental observations. It is logical to study the complicated photoinduced processes of DNA by starting from the basics single nucleobases $[19,21]$. For example, $9 H$-adenine is one of the most studied nucleobases, and its excited state properties are rather well known [19]. The absorption maximum of $9 H$-adenine at $252 \mathrm{~nm}(4.92 \mathrm{eV})$ is assigned to two close-lying ${ }^{1} \pi \rightarrow \pi^{*}$ states, which are labeled $\mathrm{L}_{a}$ and $\mathrm{L}_{b}$ [19]. Another singlet state of ${ }^{1} \mathrm{n} \rightarrow \pi^{*}$ character, located only $0.073 \mathrm{eV}$ below the ${ }^{1} \pi \rightarrow \pi^{*}$ state, may be involved in the photoexcitation as a dark state [195]. Biexponential fitting of the time-resolved spectra in the gas phase gives time constants of 40-100 fs and 0.75-1 ps for the short and long components, respectively [196-201]. These sub-picosecond time scales are considered to be fingerprints of intrabase internal conversions [19]. A number of computational investigations on $9 \mathrm{H}$-adenine have been conducted, and several minimum-energy crossing points or conical intersections connecting the PESs of the low-lying singlet states have been located [84, 87, $110,202-205]$. Two conical intersections, labeled ${ }^{2} \mathrm{E}$ and ${ }^{6} \mathrm{~S}_{1}$ following the CremerPople-Boeyens classification [206, 207], are energetically favorable. They are characterized by strong out-of-plane deformations at the $\mathrm{C} 2-\mathrm{H} 2$ and C6-N6 moieties, respectively [84, 87, 110, 202-205]. On the basis of these computational results, several principal reaction paths in the gas phase have been suggested. For example, based on linear interpolation in internal coordinates (LIIC) at the 
CASPT2//CASSCF level, Barbatti and Lischka [87] found barrierless paths to both ${ }^{2} \mathrm{E}$ and ${ }^{6} \mathrm{~S}_{1}$ conical intersections. Their findings agree with the report by Perun et al. at a similar theoretical level [84, 208]. Hassan et al. [209] reported MRCI// CASSCF calculations giving an ultrafast conversion from $\mathrm{L}_{a}$ to ${ }^{1} \mathrm{n} \rightarrow \pi^{*}$ that was followed by a steep LIIC path down to the ${ }^{6} \mathrm{~S}_{1}$ conical intersection, whereas the route toward the ${ }^{2} \mathrm{E}$ conical intersection required an activation energy of $0.21 \mathrm{eV}$. By contrast, Conti et al. [210] found the ${ }^{6} \mathrm{~S}_{1}$ conical intersection to lie $0.42 \mathrm{eV}$ above the ${ }^{1} \mathrm{n} \rightarrow \pi^{*}$ minimum at the CASPT2//CASSCF level. Semiempirical MRCI surface-hopping dynamics simulations by Fabiano and Thiel [110] indicated a two-step nonadiabatic relaxation with an initial $\sim 15-\mathrm{fs} \mathrm{S}_{2} \rightarrow \mathrm{S}_{1}$ deactivation and a subsequent $\sim 560$-fs exponential decay to the ground state $\left(S_{0}\right)$, fairly analogous to the ab initio MRCIS excited-state dynamics [87] except that the second step mainly proceeded via the ${ }^{6} \mathrm{~S}_{1}$ channel (OM2/MRCI) rather than the ${ }^{2} \mathrm{E}$ channel (MRCIS). To summarize, these studies of gas-phase $9 H$-adenine agree on some general qualitative features, for example, the presence of three closely coupling excited states around $5 \mathrm{eV}\left({ }^{1} \mathrm{n} \rightarrow \pi^{*}, \mathrm{~L}_{a}{ }^{1} \pi \rightarrow \pi^{*}\right.$, and $\left.\mathrm{L}_{b}{ }^{1} \pi \rightarrow \pi^{*}\right)$, the existence of several competing nonradiative decay channels (e.g., ${ }^{6} \mathrm{~S}_{1}$ vs ${ }^{2} \mathrm{E}$ ), and the distorted geometries at the corresponding conical intersections, while differing in mechanistic details. These investigations have laid the foundation for the subsequent exploration of real DNA systems. For further details regarding the excited-state properties and dynamics of the five nucleobases, see the recent review article by Kleinermanns et al. [19]. Most recently, Tuna et al. [211] reported that intramolecular proton transfer from the ribose $5^{\prime}-\mathrm{OH}$ group to the adenine $\mathrm{N} 3$ atom (see Fig. 1) is possibly responsible for the much shorter observed lifetime of adenosine compared with $9 H$-adenine [212].

Many experimental studies have reported distinct spectral shifts of isolated nucleobases when going from the gas phase to aqueous solution: e.g., red shifts of $9 H$-adenine and 9-methyladenine by $0.15-0.21 \mathrm{eV}$ and blue shifts of $3 H$-cytosine and 3-methylcytosine by $0.30-0.38 \mathrm{eV}$ [5, 213-215]. When going from solvated nucleobases to the corresponding DNA strands, there are only slight shifts. For example, the aqueous absorption maximum is found at $4.73 \mathrm{eV}$ for the $\mathrm{dA} / \mathrm{dT}$ mixture, at $4.78 \mathrm{eV}$ for $(\mathrm{dA})_{20} \cdot(\mathrm{dT})_{20}$, and at $4.72 \mathrm{eV}$ for $(\mathrm{dAdT})_{10} \cdot(\mathrm{dTdA})_{10}[184]$; the absorption maximum of adenosine is measured at $4.77 \mathrm{eV}$ in aqueous solution while it is at $4.82 \mathrm{eV}$ for $(\mathrm{dA})_{20}$ [216]. These solvatochromic shifts are induced by the complex electrostatic and steric environment in the condensed phase. Valiev and Kowalski [67, 74] computed the steady-state photoexcitation for a single cytosine in the native DNA environment at the QM/MM level using EOM-CCSD(T) for the QM part. They reported pronounced blue shifts of the two lowest singlet excited states, ${ }^{1} \pi \rightarrow \pi^{*}$ at $5.01 \mathrm{eV}$ and ${ }^{1} \mathrm{n} \rightarrow \pi^{*}$ at $5.79 \mathrm{eV}$ on average, compared to the gas-phase values of 4.76 and $5.24 \mathrm{eV}$ for a single cytosine, respectively. Correspondingly, the ionization potentials of all four DNA nucleobases also increase in solvated QM/MM DNA models compared with the gas phase [217]. Thiel and coworkers [113-115] reported a small steady-state blue shift $(0.09-0.17 \mathrm{eV})$ for a single adenine embedded in $(\mathrm{dA})_{10}$ and $(\mathrm{dA})_{10} \cdot(\mathrm{dT})_{10}$ relative to the absorption energy of aqueous $9 H$-adenine. Although these QM/MM 
results reflect the solvent and environmental effects in a qualitatively correct manner, they should not be directly compared to the experimental spectra, because the calculations took into account only a single QM nucleobase (neglecting other bases as well as QM interbase interactions).

Lu et al. [114, 115] carried out QM/MM nonadiabatic dynamics simulations for a single adenine embedded in single- and double-stranded oligomers (dA) 10 and $(\mathrm{dA})_{10} \cdot(\mathrm{dT})_{10}$, treating the QM adenine with the semiempirical OM2/MRCI approach. They found that the ${ }^{6} \mathrm{~S}_{1}$ and ${ }^{2} \mathrm{E}$ conical intersections (see above) remain the dominating decay channels, but the computed time constants for the monomeric excited-state decay increase dramatically, roughly by an order of magnitude compared with the gas or aqueous phase ( 4.1-5.7 vs $\sim 0.4-0.6 \mathrm{ps}$ at the same level of QM theory, see above). They identified the main reason for the much slower internal conversion as a strong lowering of the interstate coupling caused by the electrostatic environment of the DNA strands. They simulated the time-dependent fluorescence spectrum of single adenine in $(\mathrm{dA})_{10}$ (by considering the timedependent population of excited adenine during the dynamics run), which reproduced the temporal behavior of the experimental spectra in a qualitatively reasonable manner [191]. Lischka and coworkers also performed QM/MM surfacehopping studies on a single nucleobase (or its derivatives) in DNA strands [144, 218]. In their latest study [218] they employed ab initio MRCIS surfaces for a single guanine base in DNA; they observed that less than 9\% of the guanine population decayed to the ground state within the simulation time $(0.5 \mathrm{ps})$, which also implies a much longer time constant in DNA compared to that for isolated guanine $(\sim 0.22 \mathrm{ps})$. On the other hand, a single cytosine (treated with CASSCF) was reported to exhibit a slightly faster decay ( 0.48 ps [218]) when embedded in DNA than in vacuo ( 0.69 ps [219]), because of energetic factors. It should be emphasized that these monomeric models provide reasonable explanations for some experimental observations in DNA strands, but they cannot be considered conclusive because they ignore multiple-base mechanisms (see below).

Most of the published computational studies address single nucleobases without the sugar-phosphate backbone. A recent LRC-TDDFT study [220] stressed that the involvement of backbone MOs in the photoexcitation of DNA strands should not simply be neglected. It is well known that electron attachment may induce DNA bond breaking which normally happens at the sugar $\left(\mathrm{C5}^{\prime}-\mathrm{O}^{\prime}, \mathrm{C}^{\prime}-\mathrm{O}^{\prime}\right)$ and the glycosidic (N9-C1') $\sigma$ bonds (see Fig. 1) [32, 33, 59]. Theoretical modeling of this bond breaking has usually been carried out in the electronic ground state. However, according to Kumar and Sevilla [221, 222], the bond-breaking reactions could be activated in dark ${ }^{1} \pi \rightarrow \sigma^{*}$ excited states that are indirectly populated through vibronic coupling with optically bright ${ }^{1} \pi \rightarrow \pi^{*}$ states. If so, it would clearly be crucial also to reckon with backbone contributions to the photoexcitation of DNA strands. 


\subsection{Base Stacking in DNA Strands}

We now shift the focus toward models containing more than one nucleobase. A large number of theoretical studies have been carried out on the excitation of stacked bases (in vacuo, water, or solvated DNA) using various theoretical methods [223]. First of all, one should note that different base sequences give different results. Matsika and coworkers [61] compared the performance of different methods (including CIS, TDDFT, CASSCF, and CC) in the description of excited-state $\pi$-stacked nucleobases. A benchmark study by Aquino et al. [130] reported stable interbase charge-transfer states for stacked adenine-thymine and stacked guanine-cytosine, the simplest stacked base pairs. However, the nature, and especially the delocalization degree, of the initially populated excited states in real DNA systems remains a puzzle [37]. The available computational results on the localization/delocalization degree seem to be highly dependent on the stacked base sequences, configurational fluctuations, and the chosen theoretical methods (see below for detailed discussions).

Using the CIS approach, Matsika and coworkers [224, 225] studied the quenching of fluorescence in stacked 2-aminopurine-pyrimidine complexes and stacked 2-aminopurine dimers in the gas phase, as models of stacked base pairs in natural DNA. They discovered that conical intersections with interbase bonding interactions can induce some of the stacked bases to decay from charge-transfer excimers. This suggests a possible dimer mechanism of radiationless decay that might contribute to the very low fluorescence quantum yield of natural DNA.

Since electronic-structure calculations are still not practical for describing highly delocalized states in complexes containing several stacked nucleobases, the exciton model is often used for modeling the bound excitation and excitedstate energy transfer of natural DNA [226] (see Sect. 2.1.7). Applying Frenkel exciton theory to gas-phase $(\mathrm{dA})_{20} \cdot(\mathrm{dT})_{20}$ and $(\mathrm{dAdT})_{10} \cdot(\mathrm{dTdA})_{10}$, Bouvier et al. inferred in an early study [184] that dipolar coupling alone may induce delocalization after photoexcitation. In their excitonic model, the excitation energies of individual nucleobase monomers (i.e., the diagonal terms in the excitonic Hamiltonian matrix) were derived from experimental parameters and considered insensitive to the local environment. Further investigations [140, 141] on the duplexes $(\mathrm{dA})_{10} \cdot(\mathrm{dT})_{10}$ and $(\mathrm{dGdC})_{5} \cdot(\mathrm{dCdG})_{5}$ in the aqueous phase (with QM/MM) employed the same excitonic approach, which gave only a slight blue shift in the simulated absorption spectra - consistent with experimental observations that the DNA UV spectra resemble the superposition of the spectra of the monomeric bases [227]. Charge-transfer states were not included in their exciton model since only dipolar couplings (without interbase orbital overlap) were included when computing the electronic couplings (i.e., the off-diagonal terms of the excitonic Hamiltonian). Hu et al. [216] built a similar excitonic model with dipolar interactions and characterized the $\pi$-stacked adenines as hypsochromic aggregates (H-aggregates) [228] that display a blue shift of the absorption maxima. 
Based on their TDDFT calculations of stacked 9-methyladenine $\left(\mathrm{m}^{9} \mathrm{~A}\right)$ dimers and trimers in water (described with PCM), Improta and coworkers [147] interpreted the experimentally observed subpicosecond components (see Sect. 3.1) as ultrafast decay of the bright delocalized states, proceeding either via a localized monomeric pathway or via a pathway involving dark interbase chargetransfer excimers. Their theoretical calculations reproduced a typical signature of excimers, namely the slight blue shift and the decrease in oscillator strength compared with the monomers. The authors speculated that the decay components longer than 100 ps could be related to full geometric relaxation of the chargetransfer state. Using an excitonic model, Improta et al. [150] pointed out in particular that there is a fast and effective transfer in stacked adenines between bright excitonic states and dark charge-transfer states, because of their strong coupling. Recent theoretical studies $[153,157]$ on $(\mathrm{dA})_{4}$ and $\left(\mathrm{m}^{9} \mathrm{~A}\right)_{n}(n=1-5)$ at the PCM/TDDFT level, combined with spectroscopy experiments on $(\mathrm{dA})_{20}$, enriched the proposed scenario: the absorbing states of stacked adenines are bright excitonic states delocalized over up to four bases; they may rapidly localize to bright excited states on base monomers, or evolve into darker ${ }^{1} \pi \rightarrow \pi^{*}$ excimers and/or charge-transfer excimers/exciplexes. Remarkably, these features were generally found to be independent of the number of stacked adenines. According to the proposed scenario, the multiexponential UV absorption spectra can be interpreted in terms of excitons (picosecond components), neutral excimers (sub-nanosecond components), and charge-transfer states (nanosecond components). Quantum dynamics simulations (without nuclear relaxation) at the PCM/TDDFT level indicated that charge-transfer states arise from the initial excitonic states within a few femtoseconds and survive for at least $\sim 1$ ps [158].

Bittner [176] proposed a novel excitonic Hamiltonian for poly(dA)·poly(dT) on the basis of the lattice fermion model, which includes all intrastrand and interstrand excitonic coupling terms. Taking both orbital overlap and dipolar couplings into consideration, Bittner [176, 229] computed the electronic dynamics (with fixed nuclear coordinates) in vacuo and showed that delocalized excitonic states with weak interstrand coupling immediately decay into non-excitonic chargeseparated states $\left(\mathrm{e}^{-} / \mathrm{h}^{+}\right.$pairs) in the deoxythymidine (dThd) strand, but remain unchanged for several hundred femtoseconds in the deoxyadenosine (dAdo) strand. Based on INDO/S calculations and MD simulations, Voityuk [230] arrived at a similar conclusion, namely that singlet excitation energy transfer in poly $(\mathrm{dA}) \cdot$ poly (dT) is prevailing in the dT strand. However, Lange and Herbert [60] suggested a contradictory picture on the basis of LRC-TDDFT calculations on $\mathrm{Ade}_{3} \cdot \mathrm{Thy}_{3}$ (Thy $=$ thymine) in aqueous solution, which gave optically bright excitonic states that are almost localized on the adenine strand. Furthermore, averaging the excitonic states over conformations obtained from ground-state MD simulations yielded blue-shifted absorption spectra (compared with those of the base monomers) [231]. Notably, Voityuk's QM/MM-based exciton model for poly(dA)·poly (dT) [232] predicts direct population of intrastrand (rather than interstrand) charge-separated states upon UV absorption, whereas both intrastrand and 
interstrand charge-transfer states are important in the LRC-TDDFT modeling of Lange and Herbert [60].

In the $\mathrm{QM} / \mathrm{MM}$ exciton model for $(\mathrm{dA})_{10} \cdot(\mathrm{dT})_{10}$ and $(\mathrm{dGdC})_{5} \cdot(\mathrm{dCdG})_{5}$ developed by the Markovitsi group [140, 141], the delocalization extends over at least two nucleobases. This agrees with experimental evidence that the delocalization involves more than three or four bases [182]. Coincidentally, in Bittner's model [231], the excitons delocalize over at least six nucleobases. In simulations by Voityuk [232], the bright excitons spread over almost all intrastrand nucleobases in an ideal B-DNA strand $\left[(\mathrm{dA})_{n} \cdot(\mathrm{dT})_{n}(n=1-8)\right]$, while thermal fluctuations and vibronic interactions induced significant localization and reduced the average length of the excitons to around three nucleobases. By contrast, Plasser et al. [76] concluded from their $\mathrm{QM} / \mathrm{MM}[\mathrm{QM}=\mathrm{ADC}(2)]$ calculations on aqueous $(\mathrm{dAdT})_{6} \cdot(\mathrm{dTdA})_{6}$ and $(\mathrm{dGdC})_{6} \cdot(\mathrm{dCdG})_{6}$ that most excitonic and charge-transfer excited states are delocalized over at most two bases in these oligomers.

The well-known hyperchromism in DNA (i.e., the experimentally observed increase of photoabsorbance with DNA denaturation, for example through melting caused by heating) has been related to a presence of excitonic states by D'Abramo et al. [233]. These authors evaluated excitonic interactions with the perturbed matrix method (PMM) at the CASPT2//CASSCF level. Their computed (QM/MM) absorption spectra of nucleobases embedded in poly(dA) and poly (dT) show $\sim 30 \%$ greater absorbance and a slight red shift of the absorption maximum compared with poly $(\mathrm{dA}) \cdot \operatorname{poly}(\mathrm{dT})$, well matching the experimental observations. They explained this phenomenon by the higher delocalization of excitonic states in single strands than in the duplex. According to TDDFT calculations by Varsano et al. [234], $\pi$-stacking causes more significant hyperchromism than hydrogen bonding.

Over the past decade, the electronic coupling in $\mathrm{e}^{-} / \mathrm{h}^{+}$pairs and the energy transfer along $\pi$-stacking DNA strands was systematically investigated by Rösch, Voityuk, and others [235-259]. The $\mathrm{e}^{-} / \mathrm{h}^{+}$transfer in DNA strands was found to be sensitive to the base sequence and the strand conformation [260]. It was predicted that solvent effects could confine the charge delocalization to a single base pair in double-stranded (9H-guanine) $)_{n} \cdot(\text { cytosine })_{n}\left(\mathrm{Gua}_{n} \cdot \mathrm{Cyt}_{n}, n=2-9\right)$ [247] and that excess charges could also be localized on a single base in $\pi$-stacked radical-cation single strands [251, 261]. Voityuk and Davis [249] showed how DNA-protein contacts may directly affect the stability of a guanine radical cation $\left(\mathrm{h}^{+}\right)$in the dynamics of long-range hole transport. In contrast to electron transfer, the triplettriplet energy transfer in DNA strands was found to occur on the nanosecond timescale [262] (which might be associated with the very long-lived species observed experimentally) and to be less influenced by the environment [263]. A molecular switch driven by photoexcitation was designed by utilizing the chargetransfer features in DNA strands [264]. Further models for charge transfer/transport in DNA strands have been extensively discussed by several theoretical groups, for example, in [265-298]. For more detailed information, we refer the reader to some excellent reviews on these topics [299-304]. 


\subsection{Base Pairing in DNA Strands}

The pairing structure of DNA double helices is maintained by the hydrogen bonds between purines and pyrimidines. Calculations at the CC2 level of the Ade.Thy Watson-Crick base pair in the gas phase by Perun et al. [73] revealed that the hydrogen bonds also enhance the photostability of DNA. According to their results, after photoexcitation to the bright localized ${ }^{1} \pi \rightarrow \pi^{*}$ state $\left[{ }^{1} \pi \rightarrow \pi^{*}\right.$ (LE)], the base pair can easily access the dark intermolecular charge-transfer state ${ }^{1} \pi \rightarrow \pi^{*}$ $\left[{ }^{1} \pi \rightarrow \pi^{*}(\mathrm{CT})\right]$ through a conical intersection close to the Franck-Condon region. The charge separation in the ${ }^{1} \pi \rightarrow \pi^{*}$ (CT) state triggers a hydrogen-bond-mediated proton transfer from adenine to thymine that balances out the charges and leads to a minimum with biradical character. Thereafter, the base pair returns to the ground state $\left(S_{0}\right)$ through the conical intersection connecting the $S_{0}$ and ${ }^{1} \pi \rightarrow \pi^{*}$ (CT) states, which is found to be lower in energy than the minima of the bright states. Starikov et al. [305] calculated possible conformations of DNA duplexes $(\mathrm{dA})_{n} \cdot(\mathrm{dT})_{n}$ and $(\mathrm{dG})_{n} \cdot(\mathrm{dC})_{n}(n=3,4)$ at the ZINDO level and reported that their excitation energy and the contribution of the charge-transfer transition (chargetransfer exciton) are highly conformation-dependent. Taking solvent effects into account at the PCM/TDDFT level, Improta and coworkers [151] drew a different conclusion for their $(9 \text {-methyladenine })_{2} \cdot(1 \text {-methylthymine })_{2}\left[\left(\mathrm{~m}^{9} \mathrm{~A}\right)_{2} \cdot\left(\mathrm{m}^{1} \mathrm{~T}\right)_{2}\right]$ tetramer model. They asserted that the bright states are delocalized over the adeninethymine pair and that the initial excitation is followed by ultrafast localization to a single base. They did not find proton transfer to play a key role in the deexcitation of their model. A recent time-resolved experiment [306] detected species in $(\mathrm{dA})_{n} \cdot(\mathrm{dT})_{n}$ double strands $(\sim 70 \mathrm{ps})$ that are shorter-lived than those for singlestranded $(\mathrm{dA})_{\mathrm{n}}(\sim 100-200 \mathrm{ps})$ [307]. This suggests that base pairing may have significant impact on the excitation behavior of double strands, which still lacks a clear theoretical explanation.

Likewise, there is experimental and computational evidence that the photodynamics of an isolated Gua.Cyt base pair is closely related to interbase proton transfer [308-310]. The conformation of the Watson-Crick base pair was found to be the key to the photostability of Gua.Cyt [311], which may even involve double proton transfer in the gas phase [312]. There are also experiments supporting a proton-transfer mechanism in alternating $\mathrm{G} / \mathrm{C}$ double strands [e.g., $\left.(\mathrm{dGdC})_{n} \cdot(\mathrm{dCdG})_{n}\right]$, which, however, strongly depends on the base sequence [313]. For a Watson-Crick guanine-cytosine $(\mathrm{G} \cdot \mathrm{C})$ base pair embedded in native B-DNA, CASSCF/MM surface-hopping dynamics simulations by Groenhof et al. [314] suggested that the primary radiationless decay channel is a single proton transfer from $9 \mathrm{H}$-guanine to cytosine followed by efficient internal conversion. Moreover, double proton transfer (originating from the guanine N1 and the cytosine $\mathrm{N} 4$ atoms) was also observed in the simulations as a minor channel. Another mechanistic option is the so-called proton-coupled electron transfer (PCET) proton transfer accompanied by transfer of an electron in the same direction but generally not at the same time [315], which effectively results in the transfer of a 
neutral hydrogen atom. At the CASPT2//CASSCF level, stepwise double hydrogen transfer was calculated to be the most favorable decay pathway for Gua.Cyt in vacuo, among the three possible proton/hydrogen-transfer processes [315]. When embedded in a DNA duplex using the QM/MM method, the Gua.Cyt pair was still found to decay via the same pathway, with an estimated lifetime of $\sim 50 \mathrm{fs}$ [315]. However, these calculations did not explain the experimental fact that the ground-state recovery in $\mathrm{G} / \mathrm{C}$ duplexes $\left[(\mathrm{dGdC})_{9} \cdot(\mathrm{dCdG})_{9},\left(\mathrm{dG}_{4} \mathrm{dC}_{4}\right) \cdot\left(\mathrm{dC}_{4} \mathrm{dG}_{4}\right)\right.$, and $\left.\left(\mathrm{dG}_{5} \mathrm{dA}_{4} \mathrm{dG}_{5}\right) \cdot\left(\mathrm{dC}_{5} \mathrm{dT}_{4} \mathrm{dC}_{5}\right)\right]$ is much slower than in a mixture of CMP and GMP [316].

According to CASPT2//CASSCF studies of gas-phase $9 H$-adenine by Perun et al. [84, 208], the ${ }^{6} \mathrm{~S}_{1}$ decay channel with an out-of-plane amino group (see Sect. 3.2) may be suppressed when the base is paired with thymine (or uracil in RNA) through Watson-Crick hydrogen bonds. This prediction was confirmed in the QM/MM surface-hopping studies of a single adenine in $(\mathrm{dA})_{10} \cdot(\mathrm{dT})_{10}$ by Lu et al. $[114,115]$. Unlike the single-stranded $(\mathrm{dA})_{10}$, the monomeric ${ }^{6} \mathrm{~S}_{1}$ channel in the double strand is completely locked, and the ${ }^{2} \mathrm{E}$ channel becomes dominant, since it does not require geometric deformations that perturb hydrogen bonds. Similar restraints by hydrogen bonding were found for guanine in a DNA duplex in QM/MM surface-hopping simulations by Zelený et al. [218]. However, hydrogen bonding is not the reason for the slower monomeric decay in the DNA strands compared with the gas or aqueous phase (see Sect. 3.2). We note again that the QM regions were confined to single bases in these QM/MM studies, which thus disregarded mechanisms involving more than one base (e.g., proton transfer, intermolecular charge transfer, and exciton formation).

Additionally, Rak, Voityuk, and coworkers [317, 318] suggested that proton transfer and base pairing could be associated with the electronic coupling in $\pi$-stacked DNA. The coupled effects of base pairing and base stacking in water were carefully examined for $\mathrm{Gua}_{3} \cdot \mathrm{Cyt}_{3}$ and (GuaCytGua).(CytGuaCyt) by Ko and Hammes-Schiffer [319] by means of QM/MM (QM = TDDFT) calculations: in both cases, proton transfer was found to stabilize the interstrand charge-transfer state, and in (GuaCytGua) $(\mathrm{CytGuaCyt})$ it helped facilitate the nonadiabatic decay from the intrastrand to the interstrand charge-transfer state $[35,36]$.

\subsection{Pyrimidine Dimerization}

One of the most important DNA photochemical reactions is the photolesion due to UV excitation. Pyrimidine dimerization is considered to be the major cause of photolesion [5]. The main photoproducts are cyclobutane pyrimidine dimers (CPDs), and the end result may be mutagenesis, cell death, or even skin cancer. CPDs are formed by $[2+2]$-cycloaddition linking two $\mathrm{C} 5=\mathrm{C} 6$ double bonds of two neighboring pyrimidine bases (see Fig. 2) [5, 320, 321]. There is considerable debate about the mechanism of this cyclization reaction - one core issue is the multiplicity. For instance, based on time-resolved fluorescence and absorption 
Fig. 2 Left: cyclobutane pyrimidine dimer (CPD); right: 6-4 photoproduct

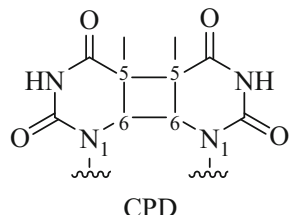

$\mathrm{CPD}$

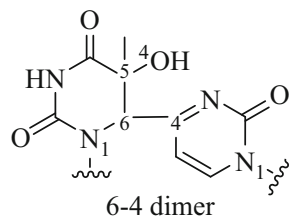

spectroscopy, Kwok et al. [322] proposed for $(\mathrm{dT})_{20}$ that formation of the photoproduct takes $\sim 140 \mathrm{ps}$ and is mediated by a biradical intermediate through selfquenching of the $T_{1}$ state, which is accessed $(\sim 1.7 \mathrm{fs})$ by an ultrafast singlet-triplet intersystem crossing. In contrast, time-resolved infrared (IR) spectroscopic experiments [180] provided strong evidence in support of the direct formation of the dimer in a singlet $\pi \rightarrow \pi^{*}$ state, within only $\sim 1$ ps after excitation. Single nucleobases were also reported to undergo an ultrafast direct dimerization in a resonance Raman study by Loppnow and coworkers [323, 324].

Robb and coworkers [325] compared two possible [2+2]-cycloaddition pathways of a stacked thymine dimer in the gas phase at the CASPT2//CASSCF level. The first one was a stepwise thermal reaction in the electronic ground state $\left(\mathrm{S}_{0}\right)$ via two biradical transition states with activation energies of about $60 \mathrm{kcal} / \mathrm{mol}$; the second one involved excitation to a singlet excited state $\left(S_{1}\right)$, which cyclizes via a barrierless concerted mechanism and returns to $S_{0}$ by an ultrafast internal conversion at the $\mathrm{S}_{0} / \mathrm{S}_{1}$ conical intersection. It is obvious that the latter pathway is favored, which is analogous to nonadiabatic cyclization reactions of stacked ethylenes. Based on similar CASPT2//CASSCF calculations in vacuo, Blancafort and Migani [326] realized that the reactive excimer in the B-DNA conformation is a dark state possessing little oscillator strength. Although the excimer is accessible when conformational and environmental effects are taken into account in the aqueous phase, the authors proposed another possible mechanism: an unreactive localized excited state is initially populated and then decays to the reactive state through avoided crossings. A PCM/TDDFT study [155] reported a barrierless [2 + 2]dimerization originating from bright ${ }^{1} \pi \rightarrow \pi^{*}$ excitons and a less favorable $6-4$ dimerization (see Fig. 2) involving a barrier and charge transfer from the $5^{\prime}$-end to the 3 '-end, without excluding monomeric decay pathways in loosely stacked bases. Dou and coworkers [327] observed in their semiclassical dynamics simulations that cyclization takes place after the excimer decays to the ground state through the $\mathrm{S}_{0} /$ $\mathrm{S}_{1}$ conical intersection and that the two cyclobutane bonds (C5-C5' and C6-C6') between two stacked thymines are then formed one by one within $\sim 110 \mathrm{fs}$.

Using CASPT2 calculations, Merchán, Serrano-Andrés, and coworkers [175, 328] rationalized the lower dimerization yield of cytosine compared with thymine: the former has a stable singlet excimer that needs to overcome a barrier (though small) to reach the $S_{0} / S_{1}$ conical intersection, while this process is downhill in the latter. The authors also proposed a barrierless non-concerted dimerization mechanism in the triplet manifold, the efficiency of which relies on the ease of the $S_{0} / T_{1}$ intersystem crossing [175, 328]. Overall, in real systems, these two mechanisms 
will be modulated by many factors such as DNA sequence, aggregation, and solvent.

Besides CPDs, 6-4 dimers (see Fig. 2) can also be found in the photoproducts as the result of nucleophilic attack, but their yield is smaller than that of CPDs by an order of magnitude [329]. These 6-4 photoproducts have also drawn much attention because they are even more mutagenic than CPDs [330]. CASPT2//CASSCF calculations by Blancafort and Migani [326] suggested that the reaction involves an oxetane-type precursor generated via a charge-transfer excited state. There is evidence [154, 329, 331] from time-resolved spectra of $(\mathrm{dT})_{20}$ and from theoretical calculations on thymine dinucleotide (TpT) that this charge-transfer state, which could be directly populated by optical excitation, is stabilized in solution compared to the gas phase [326], owing to the stabilizing interactions with the solvent and the sugar-phosphate backbone. The fact that the 6-4 addition reaction only plays a secondary role was explained with a significant energy barrier, which is also induced by dynamical solvent effects [154].

The conformational control of pyrimidine dimerization in DNA strands was widely discussed in theoretical investigations, for example in [320, 331, 332]. The probability of dimerization is highly dependent on the distance and the dihedral angle between the $\mathrm{C} 5=\mathrm{C} 6$ double bonds [320, 333]. Lewis and coworkers [331, 332] addressed the conformational fluctuations by taking snapshots from groundstate MD simulations for $(\mathrm{dT})_{20}$ and $(\mathrm{dT})_{20} \cdot(\mathrm{dA})_{20}$, which indicated that the midpoint distance $d$ between the two approaching $\mathrm{C} 5=\mathrm{C} 6$ double bonds (see Fig. 2) plays a more important role for the dimerization than the dihedral angle. By fitting to experimental data, they found the proportion of MD snapshots with $d<3.52 \AA$ to be equal to the quantum yield of the [2+2] cycloaddition. Similarly, they concluded that the 6-4 dimerization occurs when the distance between the C5 and O4 atoms (see Fig. 2) is smaller than $2.87 \AA$. Combined experimental and theoretical investigations by Lewis and coworkers $[332,334,335]$ indicated that flanking purine bases (for example, in a local sequence consisting of a purine-pyrimidinepyrimidine motif such as G-T-T) modulate the dimerization efficiency of stacked pyrimidines mainly by affecting their ground-state conformations (rather than by energy or charge transfer). Generally speaking, the quantum yield of dimerization depends on many factors, such as the kind of adjacent nucleobases [336], excitedstate dimer repair [337], quenching of dimerization [338], and ground-state donoracceptor interactions between $\pi$-stacked bases [334]

Organisms have developed a defense mechanism against photolesion caused by pyrimidine dimerization. For example, in the human body, photoinduced DNA damage is fixed by photolyases - a class of repair enzymes [292, 339-344]. The repair mechanism has been the subject of several theoretical studies that arrived at the following scenario: a reduced flavin adenine dinucleotide $\left(\mathrm{FADH}^{-}\right)$transfers one electron $\left(\mathrm{e}^{-}\right)$to the thymine-thymine dimer, the anion formed reverts back to normal thymine bases by ring opening via a radical intermediate, and the electron then returns again to FADH [342, 345-349]. For further information on this topic, we refer the reader to reviews such as [29] and [344]. 


\subsection{Other Helical Conformations and Modified Strands}

Besides the standard DNA strands discussed above, there are other uncommon helix conformations such as A-DNA and Z-DNA. The Quinn group [350] reported that the nonradiative decay takes longer for the Z-form than for the B-form of poly $(\mathrm{dCdG}) \cdot$ poly $(\mathrm{dGdC})$, with experimental monoexponential time constants of 1620 ps. By contrast, the Kohler group [351] reported that the experimentally observed nonradiative decay lifetime of $(\mathrm{dCdG})_{9} \cdot(\mathrm{dGdC})_{9}$ is independent of the helix conformation (also in the region of several picoseconds). These findings call for theoretical studies on Z-DNA to check whether the established theoretical explanations for B-DNA photodynamics carry over to the more loosely stacked Z-DNA strands. In a different context, the photoexcited Z-DNA double strands were modeled in a study of their circular dichroism spectra using the high-level symmetry-adapted cluster CI method [352].

There is also interesting research on nonstandard DNA strands. For example, DNA strands modified with tethered chromophores (e.g., ethidium [353]) and DNA assemblies containing nucleobase-like chromophores (e.g., deazaguanine and inosine $[354,355])$ were widely used to probe the DNA e ${ }^{-} / \mathrm{h}^{+}$transport processes (see Sect. 3.3). Photoinduced electron transfer in a synthetic artificial mimic of DNA strands - peptide nucleic acid - was studied computationally, since it may play a key role in the evolution of life [282, 356]. Making use of the excited-state properties of DNA strands, theoretical chemists have attempted to design photodriven molecular motors [357, 358].

\section{Conclusion and Outlook}

In this chapter we have presented a broad overview of computational studies on photoexcitation in DNA single and double strands. A wide range of excited-state theoretical models and computational techniques are available for computational chemists to simulate DNA strands in excited states. High-level ab initio quantum methods are still too expensive to model systems as complex as solvated DNA strands unless approximations are made and accuracy is sacrificed. The hybrid QM/MM approach offers a viable alternative by considering just the photoactive center at an expensive and accurate QM level, while using a simple MM force-field description for the DNA and solvent environment that may play an essential role in the photoexcitation. Semiempirical CI methods are a promising tool for the modeling of rather large photoexcited systems, after proper validation against experiments or high-level calculations. TDDFT can often be employed successfully to investigate the delocalized excitonic coupling in DNA strands, in spite of its deficiencies for charge-transfer and near-degenerate states. Static calculations can thus yield a wealth of theoretical information on DNA electronically excited states, both on spectra and excited-state potential energy surfaces. In addition, 
nonadiabatic dynamics simulations can provide a rich and detailed picture of photoinduced processes in DNA strands - including mechanisms, deactivation pathways, lifetimes, branching ratios, and time-resolved absorption and emission spectra.

However, a full understanding of the extremely complex photophysics and photochemistry in DNA strands is still an elusive goal for computational studies. There is a logical road map to proceed from simple models toward fully atomistic simulations of DNA by consecutively addressing (1) a single nucleobase in vacuo/ water, (2) a single nucleobase embedded in DNA strands, (3) multiple interacting nucleobases embedded in DNA strands, and (4) complete solvated DNA strands. At present, efforts on step (1) have established a solid understanding of isolated nucleobases in the gas phase and in water, and the research in this field has thus been moving rapidly toward steps (2) and (3) in recent years. The dramatic slowdown of the nonradiative decay in DNA strands, as observed in several timeresolved spectroscopic studies, has been rationalized both by a monomeric mechanism and by invoking delocalized excitonic states. Proton and/or hydrogen transfers through base pairing have been proposed to play an important role in the photoinduced processes of DNA, but their overall significance is still debated. Studies of base stacking have uncovered a number of potentially important effects, including excitonic delocalization, charge transfer, and charge/energy transport, but there is still considerable controversy concerning the nature of the initially generated excited state (electronic configuration and delocalization degree) and its evolution over time. Photoinduced damage to DNA is generally attributed to pyrimidine dimerization by [2+2]-cycloaddition, but there is still discussion about the detailed mechanism and alternative pathways, combined with the challenge to contribute theoretically to the design of an improved photoprotection strategy. Electronically excited states in uncommon DNA helix conformations and modified DNA strands constitute another important area of theoretical DNA research. When studying all these topics, a realistic computational modeling will not only strive for an accurate treatment of the photoactive region, but also carefully reckon with the complex chemical/biological environment including the sugar-phosphate backbone and the solvent. Progress toward a more complete understanding of DNA photochemistry seems most likely through joint efforts both from the experimental and computational sides.

Acknowledgement Z. L. is grateful for support from the CAS 100 Talent Project and from NSFC projects (Grant No. 21103213 and 91233106).

\section{References}

1. Callis PR (1983) Annu Rev Phys Chem 34:329

2. Crespo-Hernández CE, Cohen B, Hare PM, Kohler B (2004) Chem Rev 104:1977

3. Kohler B (2007) Photochem Photobiol 83:592 
4. Markovitsi D, Gustavsson T, Talbot F (2007) Photochem Photobiol Sci 6:717

5. Middleton CT, de La Harpe K, Su C, Law YK, Crespo-Hernández CE, Kohler B (2009) Annu Rev Phys Chem 60:217

6. Markovitsi D (2009) Pure Appl Chem 81:1635

7. Kohler B (2010) J Phys Chem Lett 1:2047

8. Gustavsson T, Improta R, Markovitsi D (2010) J Phys Chem Lett 1:2025

9. Markovitsi D, Gustavsson T, Banyasz A (2010) Mutat Res 704:21

10. Markovitsi D, Gustavsson T, Vayá I (2010) J Phys Chem Lett 1:3271

11. Markovitsi D, Sage E, Lewis FD, Davies J (2013) Photochem Photobiol Sci 12:1256

12. Garavelli M (2006) Theor Chem Acc 116:87

13. Shukla MK, Leszczynski J (2007) J Biomol Struct Dyn 25:93

14. González L, Escudero D, Serrano-Andrés L (2012) ChemPhysChem 13:28

15. Plasser F, Barbatti M, Aquino AJA, Lischka H (2012) Theor Chem Acc 131:1073

16. Cornish-Bowden A (1985) Nucleic Acids Res 13:3021

17. IUPAC-IUB Commission (1970) Eur J Biochem 15:203

18. de Vries MS, Hobza P (2007) Annu Rev Phys Chem 58:585

19. Kleinermanns K, Nachtigallová D, de Vries MS (2013) Int Rev Phys Chem 32:308

20. Frenkel J (1931) Phys Rev 37:1276

21. Saigusa H (2006) J Photochem Photobiol C 7:197

22. Yarkony DR (2011) Chem Rev 112:481

23. Fabiano E, Lan Z, Lu Y, Thiel W (2011) In: Domcke W, Yarkony DR, Köppel H (eds) Conical intersections II: theory, computation and experiment, vol 17, Advanced series in physical chemistry. World Scientific, Singapore, p 463

24. Abramczyk H (2012) Vib Spectrosc 58:1

25. Serrano-Andrés L, Merchán M (2009) J Photochem Photobiol C 10:21

26. Volkovova K, Bilanicova D, Bartonova A, Letašiová S, Dusinska M (2012) Environ Health 11:S12

27. Wondrak GT (2007) Curr Opin Investig Drugs 8:390

28. Hruza LL, Pentland AP (1993) J Invest Dermatol 100:S35

29. Cadet J, Mouret S, Ravanat JL, Douki T (2012) Photochem Photobiol 88:1048

30. Rossle SC, Frank I (2009) Front Biosci 14:4862

31. Virshup AM, Punwong C, Pogorelov TV, Lindquist BA, Ko C, Martínez TJ (2008) J Phys Chem B 113:3280

32. Simons J (2006) Acc Chem Res 39:772

33. Kumar A, Sevilla MD (2010) Chem Rev 110:7002

34. Vayá I, Gustavsson T, Miannay F-A, Douki T, Markovitsi D (2010) J Am Chem Soc 132:11834

35. Genereux JC, Barton JK (2010) Chem Rev 110:1642

36. Teo YN, Kool ET (2012) Chem Rev 112:4221

37. Nielsen LM, Hoffmann SV, Nielsen SB (2013) Photochem Photobiol Sci 12:1273

38. Pyykkö P, Stanton JF (2012) Chem Rev 112:1

39. Thiel W (2011) Angew Chem Int Ed 50:9216

40. Lyakh DI, Musiał M, Lotrich VF, Bartlett RJ (2012) Chem Rev 112:182

41. Cremer D (2011) WIREs Comput Mol Sci 1:509

42. Cohen AJ, Mori-Sánchez P, Yang W (2012) Chem Rev 112:289

43. Thiel W (1996) In: Prigogine I, Rice SA (eds) New methods in computational quantum mechanics, vol 93, Advances in chemical physics. Wiley, New York, p 703

44. Thiel W (2014) WIREs Comput Mol Sci 4:145

45. Yarkony DR (1996) Rev Mod Phys 68:985

46. Bernardi F, Olivucci M, Robb MA (1996) Chem Soc Rev 25:321

47. Yarkony DR (1998) Acc Chem Res 31:511 
48. Domcke W, Yarkony DR, Köppel H (eds) (2004) Conical intersections I: electronic structure, dynamics and spectroscopy, vol 15, Advanced series in physical chemistry. World Scientific, Singapore

49. Domcke W, Yarkony DR, Köppel H (eds) (2011) Conical intersections II: theory, computation and experiment, vol 17, Advanced series in physical chemistry. World Scientific, Singapore

50. Dreuw A, Head-Gordon M (2005) Chem Rev 105:4009

51. Schreiber M, Silva-Junior MR, Sauer SPA, Thiel W (2008) J Chem Phys 128:134110

52. Silva-Junior MR, Schreiber M, Sauer SPA, Thiel W (2008) J Chem Phys 129:104103

53. Sauer SPA, Schreiber M, Silva-Junior MR, Thiel W (2009) J Chem Theory Comput 5:555

54. Silva-Junior MR, Sauer SPA, Schreiber M, Thiel W (2010) Mol Phys 108:453

55. Silva-Junior MR, Schreiber M, Sauer SPA, Thiel W (2010) J Chem Phys 133:174318

56. Shavitt I (1977) In: Schaefer HF III (ed) Methods of electronic structure theory, vol 3, Modern theoretical chemistry. Plenum, New York, p 189

57. Sherrill CD, Schaefer HF III (1999) In: Löwdin P-O, Sabin JR, Zerner MC, Brändas E (eds) Advanced quantum chemistry, vol 34. Academic Press, San Diego, p 143

58. Shukla MK, Leszczynski J (eds) (2008) Radition induced molecular phenomena in nucleic acids, vol 5, Challenges and advances in computational chemistry and physics. Springer, Amsterdam

59. Gu J, Leszczynski J, Schaefer HF III (2012) Chem Rev 112:5603

60. Lange AW, Herbert JM (2009) J Am Chem Soc 131:3913

61. Kozak CR, Kistler KA, Lu Z, Matsika S (2010) J Phys Chem B 114:1674

62. Subotnik JE (2011) J Chem Phys 135:071104

63. Riley KE, Pitonák M, Jurecka P, Hobza P (2010) Chem Rev 110:5023

64. Christiansen O, Koch H, Jørgensen P (1995) Chem Phys Lett 243:409

65. Stanton JF, Bartlett RJ (1993) J Chem Phys 98:7029

66. Kowalski K, Valiev M (2008) Int J Quantum Chem 108:2178

67. Kowalski K, Valiev M (2008) J Phys Chem A 112:5538

68. Szalay PG (2013) Int J Quantum Chem 113:1821

69. Fan PD, Valiev M, Kowalski K (2008) Chem Phys Lett 458:205

70. Szalay PG, Watson T, Perera A, Lotrich VF, Bartlett RJ (2012) J Phys Chem A 116:6702

71. Szalay PG, Watson T, Perera A, Lotrich V, Fogarasi G, Bartlett RJ (2012) J Phys Chem A 116:8851

72. Szalay PG, Watson T, Perera A, Lotrich V, Bartlett RJ (2013) J Phys Chem A 117:3149

73. Perun S, Sobolewski AL, Domcke W (2006) J Phys Chem A 110:13238

74. Valiev M, Kowalski K (2006) J Chem Phys 125:211101

75. Epifanovsky E, Kowalski K, Fan PD, Valiev M, Matsika S, Krylov AI (2008) J Phys Chem A 112:9983

76. Plasser F, Aquino AJA, Hase WL, Lischka H (2012) J Phys Chem A 116:11151

77. Roos BO (1980) Int J Quantum Chem 17:175

78. Knowles PJ, Werner H-J (1985) Chem Phys Lett 115:259

79. Werner H-J, Knowles PJ (1985) J Chem Phys 82:5053

80. Roos BO (2007) In: Lawley KP (ed) Ab initio methods in quantum chemistry II, vol 69, Advances in chemical physics. Wiley, Chichester, p 399

81. Szalay PG, Müller T, Gidofalvi G, Lischka H, Shepard R (2012) Chem Rev 112:108

82. Malmqvist P-Å, Rendell A, Roos BO (1990) J Phys Chem 94:5477

83. Bearpark MJ, Ogliaro F, Vreven T, Boggio-Pasqua M, Frisch MJ, Larkin SM, Morrison M, Robb MA (2007) J Photochem Photobiol. A 190:207

84. Perun S, Sobolewski AL, Domcke W (2005) J Am Chem Soc 127:6257

85. Yamazaki S, Domcke W (2008) J Phys Chem A 112:7090

86. Yamazaki S, Domcke W, Sobolewski AL (2008) J Phys Chem A 112:11965

87. Barbatti M, Lischka H (2008) J Am Chem Soc 130:6831

88. Andersson K, Malmqvist P-Å, Roos BO, Sadlej AJ, Wolinski K (1990) J Phys Chem 94:5483

89. Andersson K, Malmqvist P-Å, Roos BO (1992) J Chem Phys 96:1218

90. Dewar MJS, Zoebisch EG, Healy EF, Stewart JJP (1985) J Am Chem Soc 107:3902 
91. Stewart JJP (1989) J Comput Chem 10:209

92. Stewart JJP (1989) J Comput Chem 10:221

93. Stewart JJP (1991) J Comput Chem 12:320

94. Stewart JJP (2004) J Mol Model 10:155

95. Stewart JJP (2007) J Mol Model 13:1173

96. Stewart JJP (2013) J Mol Model 19:1

97. Kolb M (1991) Ph.D. Thesis, Universität Wuppertal

98. Kolb M, Thiel W (1993) J Comput Chem 14:775

99. Weber W (1996) Ph.D. Thesis, Universität Zürich

100. Weber W, Thiel W (2000) Theor Chem Acc 103:495

101. Scholten M (2003) Ph.D. Thesis, Heinrich-Heine-Universität Düsseldorf

102. Ridley J, Zerner M (1973) Theor Chim Act 32:111

103. Ridley JE, Zerner MC (1976) Theor Chim Act 42:223

104. Granucci G, Toniolo A (2000) Chem Phys Lett 325:79

105. Voityuk AA (2006) Chem Phys Lett 427:177

106. Granucci G, Persico M, Toniolo A (2001) J Chem Phys 114:10608

107. Alexandrova AN, Tully JC, Granucci G (2010) J Phys Chem B 114:12116

108. Voityuk AA (2013) WIREs Comput Mol Sci 3:515

109. Silva-Junior MR, Thiel W (2010) J Chem Theory Comput 6:1546

110. Fabiano E, Thiel W (2008) J Phys Chem A 112:6859

111. Lan Z, Fabiano E, Thiel W (2009) ChemPhysChem 10:1225

112. Lan Z, Fabiano E, Thiel W (2009) J Phys Chem B 113:3548

113. Lan Z, Lu Y, Fabiano E, Thiel W (2011) ChemPhysChem 12:1989

114. Lu Y, Lan ZG, Thiel W (2011) Angew Chem Int Ed 50:6864

115. Lu Y, Lan Z, Thiel W (2012) J Comput Chem 33:1225

116. Heggen B, Lan Z, Thiel W (2012) Phys Chem Chem Phys 14:8137

117. Casida ME, Huix-Rotllant M (2012) Annu Rev Phys Chem 63:287

118. Dreuw A, Head-Gordon M (2004) J Am Chem Soc 126:4007

119. Levine BG, Ko C, Quenneville J, Martínez TJ (2006) Mol Phys 104:1039

120. Baer R, Livshits E, Salzner U (2010) Annu Rev Phys Chem 61:85

121. Jacquemin D, Wathelet V, Perpète EA, Adamo C (2009) J Chem Theory Comput 5:2420

122. Jensen L, Govind N (2009) J Phys Chem A 113:9761

123. Baer R, Neuhauser D (2005) Phys Rev Lett 94:043002

124. Livshits E, Baer R (2007) Phys Chem Chem Phys 9:2932

125. Yanai T, Tew DP, Handy NC (2004) Chem Phys Lett 393:51

126. Adamo C, Scuseria GE, Barone V (1999) J Chem Phys 111:2889

127. Adamo C, Barone V (1999) J Chem Phys 110:6158

128. Zhao Y, Truhlar DG (2006) J Phys Chem A 110:13126

129. Zhao Y, Truhlar D (2008) Theor Chem Acc 120:215

130. Aquino AJ, Nachtigallová D, Hobza P, Truhlar DG, Hättig C, Lischka H (2011) J Comput Chem 32:1217

131. Barbatti M, Lan Z, Crespo-Otero R, Szymczak JJ, Lischka H, Thiel W (2012) J Chem Phys 137:22A503

132. Tavernelli I, Curchod BFE, Rothlisberger U (2009) J Chem Phys 131:196101

133. Tapavicza E, Tavernelli I, Rothlisberger U, Filippi C, Casida ME (2008) J Chem Phys 129:124108

134. Tavernelli I, Tapavicza E, Rothlisberger U (2009) J Mol Struc Theochem 914:22

135. Grimme S, Waletzke M (1999) J Chem Phys 111:5645

136. Schirmer J (1982) Phys Rev A 26:2395

137. Trofimov AB, Stelter G, Schirmer J (2002) J Chem Phys 117:6402

138. Trofimov AB, Krivdina IL, Weller J, Schirmer J (2006) Chem Phys 329:1

139. Wannier GH (1937) Phys Rev 52:191

140. Emanuele E, Markovitsi D, Millié P, Zakrzewska K (2005) ChemPhysChem 6:1387

141. Emanuele E, Zakrzewska K, Markovitsi D, Lavery R, Millié P (2005) J Phys Chem B 109:16109 
142. Senn HM, Thiel W (2007) In: Reiher M (ed) Atomistic approaches in modern biology, vol 268, Topics in current chemistry. Springer, Berlin, p 173

143. Senn HM, Thiel W (2009) Angew Chem Int Ed 48:1198

144. Nachtigallová D, Zelený T, Ruckenbauer M, Müller T, Barbatti M, Hobza P, Lischka H (2010) J Am Chem Soc 132:8261

145. Cramer CJ, Truhlar DG (1999) Chem Rev 99:2161

146. Orozco M, Luque FJ (2000) Chem Rev 100:4187

147. Santoro F, Barone V, Improta R (2007) Proc Natl Acad Sci USA 104:9931

148. Improta R (2008) Phys Chem Chem Phys 10:2656

149. Santoro F, Barone V, Improta R (2008) ChemPhysChem 9:2531

150. Improta R, Santoro F, Barone V, Lami A (2009) J Phys Chem A 113:15346

151. Santoro F, Barone V, Improta R (2009) J Am Chem Soc 131:15232

152. Santoro F, Barone V, Lami A, Improta R (2010) Phys Chem Chem Phys 12:4934

153. Improta R, Barone V (2011) Angew Chem Int Ed 50:12016

154. Banyasz A, Douki T, Improta R, Gustavsson T, Onidas D, Vayá I, Perron M, Markovitsi D (2012) J Am Chem Soc 134:14834

155. Improta R (2012) J Phys Chem B 116:14261

156. Dargiewicz M, Biczysko M, Improta R, Barone V (2012) Phys Chem Chem Phys 14:8981

157. Banyasz A, Gustavsson T, Onidas D, Changenet-Barret P, Markovitsi D, Improta R (2013) Chem Eur J 19:3762

158. Santoro F, Improta R, Avila F, Segado M, Lami A (2013) Photochem Photobiol Sci 12:1527

159. Kamiya M (1978) Biochim Biophys Acta 517:527

160. Marian CM, Schneider F, Kleinschmidt M, Tatchen J (2002) Eur Phys J D 20:357

161. Marian CM, Kleinschmidt M, Tatchen J (2008) Chem Phys 347:346

162. González-Luque R, Climent T, González-Ramírez I, Merchán M, Serrano-Andrés L (2010) J Chem Theory Comput 6:2103

163. Richter M, Marquetand P, González-Vázquez J, Sola I, González L (2012) J Phys Chem Lett 3:3090

164. Worth GA, Cederbaum LS (2004) Annu Rev Phys Chem 55:127

165. Ben-Nun M, Martínez TJ (2002) In: Prigogine I, Rice SA (eds) Advances in chemical physics, vol 121. Wiley, New York, p 439

166. Levine BG, Martínez TJ (2007) Annu Rev Phys Chem 58:613

167. Tully JC (1990) J Chem Phys 93:1061

168. Wang H, Thoss M (2003) J Chem Phys 119:1289

169. Stock G, Thoss M (2005) In: Rice SA (ed) Advances in chemical physics, vol 131. Wiley, New York, p 243

170. Jasper AW, Nangia S, Zhu C, Truhlar DG (2006) Acc Chem Res 39:101

171. Dou Y, Liu Z, Yuan S, Zhang W, Tang H, Zhao J, Fang W, Lo GV (2013) Int J Biol Macromol 52:358

172. Chung WC, Lan Z, Ohtsuki Y, Shimakura N, Domcke W, Fujimura Y (2007) Phys Chem Chem Phys 9:2075

173. Nachtigallová D, Hobza P, Ritze H-H (2008) Phys Chem Chem Phys 10:5689

174. Tachikawa H, Kawabata H (2008) Chem Phys Lett 462:321

175. Serrano-Pérez JJ, González-Ramírez I, Coto PB, Merchán M, Serrano-Andrés L (2008) J Phys Chem B 112:14096

176. Bittner ER (2006) J Chem Phys 125:094909

177. Tonzani S, Schatz GC (2008) J Am Chem Soc 130:7607

178. Olaso-González G, Merchán M, Serrano-Andrés L (2009) J Am Chem Soc 131:4368

179. Gustavsson T, Sharonov A, Onidas D, Markovitsi D (2002) Chem Phys Lett 356:49

180. Crespo-Hernández CE, Cohen B, Kohler B (2005) Nature 436:1141

181. Wagner OI, Esposito A, Köhler B, Chen C-W, Shen C-P, Wu G-H, Butkevich E, Mandalapu S, Wenzel D, Wouters FS, Klopfenstein DR (2009) Proc Natl Acad Sci USA 106:19605 
182. Buchvarov I, Wang Q, Raytchev M, Trifonov A, Fiebig T (2007) Proc Natl Acad Sci USA $104: 4794$

183. Fiebig T (2009) J Phys Chem B 113:9348

184. Bouvier B, Dognon J-P, Lavery R, Markovitsi D, Millié P, Onidas D, Zakrzewska K (2003) J Phys Chem B 107:13512

185. Onidas D, Gustavsson T, Lazzarotto E, Markovitsi D (2007) Phys Chem Chem Phys 9:5143

186. Onidas D, Gustavsson T, Lazzarotto E, Markovitsi D (2007) J Phys Chem B 111:9644

187. Rashbah EI, Sturge MD (1982) Excitons. North-Holland, Amsterdam

188. Davydov AS (1971) Theory of molecular excitons. Plenum Press, New York

189. Vayá I, Gustavsson T, Douki T, Berlin Y, Markovitsi D (2012) J Am Chem Soc 134:11366

190. Schwalb NK, Temps F (2008) Science 322:243

191. Kwok W-M, Ma C, Phillips DL (2006) J Am Chem Soc 128:11894

192. Holm AIS, Nielsen LM, Kohler B, Hoffmann SV, Nielsen SB (2010) Phys Chem Chem Phys $12: 3426$

193. Nielsen LM, Hoffmann SV, Nielsen SB (2012) Chem Commun 48:10425

194. Doorley GW, Wojdyla M, Watson GW, Towrie M, Parker AW, Kelly JM, Quinn SJ (2013) J Phys Chem Lett 4:2739

195. Fucaloro AF, Forster LS (1971) J Am Chem Soc 93:6443

196. Ullrich S, Schultz T, Zgierski MZ, Stolow A (2004) J Am Chem Soc 126:2262

197. Ullrich S, Schultz T, Zgierski MZ, Stolow A (2004) Phys Chem Chem Phys 6:2796

198. Canuel C, Mons M, Piuzzi F, Tardivel B, Dimicoli I, Elhanine M (2005) J Chem Phys 122:074316

199. Ritze H-H, Lippert H, Samoylova E, Smith VR, Hertel IV, Radloff W, Schultz T (2005) J Chem Phys 122:224320

200. Satzger H, Townsend D, Zgierski MZ, Patchkovskii S, Ullrich S, Stolow A (2006) Proc Natl Acad Sci USA 103:10196

201. Samoylova E, Lippert H, Ullrich S, Hertel IV, Radloff W, Schultz T (2005) J Am Chem Soc 127:1782

202. Barbatti M, Lischka H (2007) J Phys Chem A 111:2852

203. Serrano-Andrés L, Merchán M, Borin AC (2006) Chem Eur J 12:6559

204. Serrano-Andrés L, Merchán M, Borin AC (2006) Proc Natl Acad Sci USA 103:8691

205. Marian CM (2005) J Chem Phys 122:104314

206. Cremer D, Pople JA (1975) J Am Chem Soc 97:1354

207. Boeyens JCA (1978) J Cryst Mol Struct 8:317

208. Perun S, Sobolewski AL, Domcke W (2005) Chem Phys 313:107

209. Hassan WMI, Chung WC, Shimakura N, Koseki S, Kono H, Fujimura Y (2010) Phys Chem Chem Phys 12:5317

210. Conti I, Garavelli M, Orlandi G (2009) J Am Chem Soc 131:16108

211. Tuna D, Sobolewski AL, Domcke W (2014) J Phys Chem A 118:122

212. Asami H, Yagi K, Ohba M, Urashima S, Saigusa H (2013) Chem Phys 419:84

213. Clark LB, Peschel GG, Tinoco I (1965) J Phys Chem 69:3615

214. Li L, Lubman DM (1987) Anal Chem 59:2538

215. Du H, Fuh R-CA, Li J, Corkan LA, Lindsey JS (1998) Photochem Photobiol 68:141

216. Hu L, Zhao Y, Wang F, Chen G, Ma C, Kwok W-M, Phillips DL (2007) J Phys Chem B 111:11812

217. Cauët E, Valiev M, Weare JH (2010) J Phys Chem B 114:5886

218. Zelený T, Ruckenbauer M, Aquino AJA, Müller T, Lankaš F, Dršata T, Hase WL, Nachtigallová D, Lischka H (2012) J Am Chem Soc 134:13662

219. Barbatti M, Aquino AJA, Szymczak JJ, Nachtigallová D, Lischka H (2011) Phys Chem Chem Phys 13:6145

220. Li JH, Chai JD, Guo GY, Hayashi M (2012) Phys Chem Chem Phys 14:9092

221. Kumar A, Sevilla MD (2008) J Am Chem Soc 130:2130

222. Kumar A, Sevilla MD (2009) ChemPhysChem 10:1426 
223. Šponer J, Šponer JE, Mládek A, Jurečka P, Banáš P, Otyepka M (2013) Biopolymers 99:978 224. Liang J, Nguyen QL, Matsika S (2013) Photochem Photobiol Sci 12:1387

225. Liang J, Matsika S (2011) J Am Chem Soc 133:6799

226. Markovitsi D, Small G (2002) Chem Phys 275:VII

227. Eisinger J, Shulman RG (1968) Science 161:1311

228. Kasha M, Rawls HR, El-Bayoumi MA (1965) Pure Appl Chem 11:371

229. Bittner ER (2007) J Photochem Photobiol A 190:328

230. Voityuk AA (2010) Phys Chem Chem Phys 12:7403

231. Czader A, Bittner ER (2008) J Chem Phys 128:035101

232. Voityuk AA (2013) Photochem Photobiol Sci 12:1303

233. D'Abramo M, Castellazzi CL, Orozco M, Amadei A (2013) J Phys Chem B 117:8697

234. Varsano D, Di Felice R, Marques MAL, Rubio A (2006) J Phys Chem B 110:7129

235. Voityuk AA, Rösch N, Bixon M, Jortner J (2000) J Phys Chem B 104:9740

236. Voityuk AA, Jortner J, Bixon M, Rösch N (2000) Chem Phys Lett 324:430

237. Voityuk AA, Siriwong K, Rösch N (2001) Phys Chem Chem Phys 3:5421

238. Voityuk AA, Jortner J, Bixon M, Rösch N (2001) J Chem Phys 114:5614

239. Voityuk AA, Rösch N (2002) J Chem Phys 117:5607

240. Jortner J, Bixon M, Voityuk AA, Rösch N (2002) J Phys Chem A 106:7599

241. Voityuk AA, Rösch N (2002) J Phys Chem B 106:3013

242. Rak J, Voityuk AA, Marquez A, Rösch N (2002) J Phys Chem B 106:7919

243. Siriwong K, Voityuk AA, Newton MD, Rösch N (2003) J Phys Chem B 107:2595

244. Voityuk AA, Siriwong K, Rösch N (2004) Angew Chem Int Ed 43:624

245. Voityuk AA (2005) J Phys Chem B 109:17917

246. Voityuk AA (2005) J Chem Phys 123:034903

247. Voityuk AA (2005) J Chem Phys 122:204904

248. Voityuk AA (2007) Chem Phys Lett 439:162

249. Voityuk AA, Davis WB (2007) J Phys Chem B 111:2976

250. Voityuk AA (2007) J Phys Chem C 111:7207

251. Blancafort L, Voityuk AA (2007) J Phys Chem A 111:4714

252. Voityuk AA, Duran M (2008) J Phys Chem C 112:1672

253. Voityuk AA (2008) J Chem Phys 128:115101

254. Félix M, Voityuk AA (2008) J Phys Chem A 112:9043

255. Siriwong K, Voityuk AA (2008) J Phys Chem B 112:8181

256. Voityuk AA (2008) Chem Phys Lett 451:153

257. Voityuk AA (2009) J Phys Chem B 113:14365

258. Voityuk AA (2009) Phys Chem Chem Phys 11:10608

259. Félix M, Voityuk AA (2011) Int J Quantum Chem 111:191

260. Migliore A, Corni S, Varsano D, Klein ML, Di Felice R (2009) J Phys Chem B 113:9402

261. Blancafort L, Voityuk AA (2006) J Phys Chem A 110:6426

262. Curutchet C, Voityuk AA (2011) Angew Chem Int Ed 50:1820

263. Curutchet C, Voityuk AA (2011) Chem Phys Lett 512:118

264. Řeha D, Voityuk AA, Harris SA (2010) ACS Nano 4:5737

265. Berlin YA, Burin AL, Ratner MA (2000) Superlattices Microstruct 28:241

266. Berlin YA, Burin AL, Ratner MA (2000) J Phys Chem A 104:443

267. Dekker C, Ratner MA (2001) Phys World 14:29

268. Berlin YA, Burin AL, Ratner MA (2001) J Am Chem Soc 123:260

269. Kurnikov IV, Tong GSM, Madrid M, Beratan DN (2002) J Phys Chem B 106:7

270. Tong GSM, Kurnikov IV, Beratan DN (2002) J Phys Chem B 106:2381

271. Berlin YA, Burin AL, Ratner MA (2002) Chem Phys 275:61

272. Grozema FC, Siebbeles LDA, Berlin YA, Ratner MA (2002) ChemPhysChem 3:536

273. Beljonne D, Pourtois G, Ratner MA, Brédas JL (2003) J Am Chem Soc 125:14510

274. LeBard DN, Lilichenko M, Matyushov DV, Berlin YA, Ratner MA (2003) J Phys Chem B 107:14509 
275. Starikov EB (2004) Mod Phys Lett B 18:825

276. Hennig D, Starikov EB, Archilla JFR, Palmero F (2004) J Biol Phys 30:227

277. Yamada H, Starikov EB, Hennig D, Archilla JF (2005) Eur Phys J E 17:149

278. Senthilkumar K, Grozema FC, Guerra CF, Bickelhaupt FM, Lewis FD, Berlin YA, Ratner MA, Siebbeles LDA (2005) J Am Chem Soc 127:14894

279. Starikov EB, Fujita T, Watanabe H, Sengoku Y, Tanaka S, Wenzel W (2006) Mol Sim 32:759

280. Prytkova TR, Beratan DN, Skourtis SS (2007) Proc Natl Acad Sci USA 104:802

281. Yamada H, Starikov EB, Hennig D (2007) Eur Phys J B 59:185

282. Hatcher E, Balaeff A, Keinan S, Venkatramani R, Beratan DN (2008) J Am Chem Soc 130:11752

283. Grozema FC, Tonzani S, Berlin YA, Schatz GC, Siebbeles LDA, Ratner MA (2008) J Am Chem Soc 130:5157

284. Kubař T, Elstner M (2008) J Phys Chem B 112:8788

285. Kubař T, Woiczikowski PB, Cuniberti G, Elstner M (2008) J Phys Chem B 112:7937

286. Grozema FC, Tonzani S, Berlin YA, Schatz GC, Siebbeles LDA, Ratner MA (2009) J Am Chem Soc 131:14204

287. Kubař T, Kleinekathöfer U, Elstner M (2009) J Phys Chem B 113:13107

288. Kubař T, Elstner M (2009) J Phys Chem B 113:5653

289. Keinan S, Venkatramani R, Balaeff A, Beratan DN (2010) J Phys Chem C 114:20496

290. Woiczikowski PB, Kubař T, Gutiérrez R, Cuniberti G, Elstner M (2010) J Chem Phys 133:035103

291. Gutiérrez R, Caetano R, Woiczikowski PB, Kubař T, Elstner M, Cuniberti G (2010) New J Phys 12:023022

292. Woiczikowski PB, Steinbrecher T, Kubař T, Elstner M (2011) J Phys Chem B 115:9846

293. Wolter M, Woiczikowski PB, Elstner M, Kubař T (2012) Phys Rev B 85:075101

294. Berlin YA, Voityuk AA, Ratner MA (2012) ACS Nano 6:8216

295. Renaud N, Berlin YA, Ratner MA (2013) Proc Natl Acad Sci USA 110:14867

296. Renaud N, Berlin YA, Lewis FD, Ratner MA (2013) J Am Chem Soc 135:3953

297. Wolter M, Elstner M, Kubař T (2013) J Chem Phys 139:125102

298. Kubař T, Elstner M (2013) Phys Chem Chem Phys 15:5794

299. Schuster GB (ed) (2004) Long-range charge transfer in DNA II, vol 237, Topics in current chemistry. Springer, Berlin

300. Schuster GB (ed) (2004) Long-range charge transfer in DNA I, vol 236, Topics in current chemistry. Springer, Berlin

301. Chakraborty T (ed) (2007) Charge migration in DNA. Springer, Berlin

302. Rösch N, Voityuk AA (2004) In: Schuster GB (ed) Long-range charge transfer in DNA II, vol 237, Topics in current chemistry. Springer, Berlin, p 37

303. Siriwong K, Voityuk AA (2012) WIREs Comput Mol Sci 2:780

304. Venkatramani R, Keinan S, Balaeff A, Beratan DN (2011) Coord Chem Rev 255:635

305. Starikov EB, Cuniberti G, Tanaka S (2009) J Phys Chem B 113:10428

306. Chen J, Thazhathveetil AK, Lewis FD, Kohler B (2013) J Am Chem Soc 135:10290

307. Pan Z, Chen J, Schreier WJ, Kohler B, Lewis FD (2012) J Phys Chem B 116:698

308. Sobolewski AL, Domcke W (2004) Phys Chem Chem Phys 6:2763

309. Sobolewski AL, Domcke W, Hättig C (2005) Proc Natl Acad Sci USA 102:17903

310. Schwalb NK, Temps F (2007) J Am Chem Soc 129:9272

311. Abo-Riziq A, Grace L, Nir E, Kabelac M, Hobza P, de Vries MS (2005) Proc Natl Acad Sci USA 102:20

312. Yamazaki S, Taketsugu T (2012) Phys Chem Chem Phys 14:8866

313. de La Harpe K, Crespo-Hernández CE, Kohler B (2009) J Am Chem Soc 131:17557

314. Groenhof G, Schäfer LV, Boggio-Pasqua M, Goette M, Grubmüller H, Robb MA (2007) J Am Chem Soc 129:6812

315. Sauri V, Gobbo JP, Serrano-Pérez JJ, Lundberg M, Coto PB, Serrano-Andrés L, Borin AC, Lindh R, Merchán M, Roca-Sanjuán D (2013) J Chem Theory Comput 9:481 
316. Crespo-Hernández CE, de La Harpe K, Kohler B (2008) J Am Chem Soc 130:10844

317. Rak J, Makowska J, Voityuk AA (2006) Chem Phys 325:567

318. Sadowska-Aleksiejew A, Rak J, Voityuk AA (2006) Chem Phys Lett 429:546

319. Ko C, Hammes-Schiffer S (2013) J Phys Chem Lett 4:2540

320. Law YK, Azadi J, Crespo-Hernández CE, Olmon E, Kohler B (2008) Biophys J 94:3590

321. Schreier WJ, Schrader TE, Koller FO, Gilch P, Crespo-Hernández CE, Swaminathan VN, Carell T, Zinth W, Kohler B (2007) Science 315:625

322. Kwok W-M, Ma C, Phillips DL (2008) J Am Chem Soc 130:5131

323. Billinghurst BE, Loppnow GR (2006) J Phys Chem A 110:2353

324. Yarasi S, Brost P, Loppnow GR (2007) J Phys Chem A 111:5130

325. Boggio-Pasqua M, Groenhof G, Schäfer LV, Grubmüller H, Robb MA (2007) J Am Chem Soc 129:10996

326. Blancafort L, Migani A (2007) J Am Chem Soc 129:14540

327. Yuan S, Zhang W, Liu L, Dou Y, Fang W, Lo GV (2011) J Phys Chem A 115:13291

328. Roca-Sanjuán D, Olaso-González G, González-Ramírez I, Serrano-Andrés L, Merchán M (2008) J Am Chem Soc 130:10768

329. Marguet S, Markovitsi D (2005) J Am Chem Soc 127:5780

330. Friedberg EC, Walker GC, Siede W (1995) DNA repair and mutagenesis. ASM Press, Washington

331. McCullagh M, Hariharan M, Lewis FD, Markovitsi D, Douki T, Schatz GC (2010) J Phys Chem B 114:5215

332. Hariharan M, McCullagh M, Schatz GC, Lewis FD (2010) J Am Chem Soc 132:12856

333. Johnson AT, Wiest O (2007) J Phys Chem B 111:14398

334. Pan Z, Hariharan M, Arkin JD, Jalilov AS, McCullagh M, Schatz GC, Lewis FD (2011) J Am Chem Soc 133:20793

335. Pan Z, McCullagh M, Schatz GC, Lewis FD (2011) J Phys Chem Lett 2:1432

336. Kundu LM, Linne U, Marahiel M, Carell T (2004) Chem Eur J 10:5697

337. Holman MR, Ito T, Rokita SE (2007) J Am Chem Soc 129:6

338. Cannistraro VJ, Taylor JS (2009) J Mol Biol 392:1145

339. Tuteja N, Tuteja R (2001) Crit Rev Biochem Mol Biol 36:261

340. Harrison CB, O'Neil LL, Wiest O (2005) J Phys Chem A 109:7001

341. Essen LO, Klar T (2006) Cell Mol Life Sci 63:1266

342. Kao Y-T, Saxena C, Wang L, Sancar A, Zhong D (2007) Cell Biochem Biophys 48:32

343. Liu Z, Tan C, Guo X, Kao Y-T, Li J, Wang L, Sancar A, Zhong D (2011) Proc Natl Acad Sci USA 108:14831

344. Faraji S, Dreuw A (2014) Annu Rev Phys Chem 65:275

345. Masson F, Laino T, Rothlisberger U, Hutter J (2009) ChemPhysChem 10:400

346. Harbach PHP, Borowka J, Bohnwagner M-V, Dreuw A (2010) J Phys Chem Lett 1:2556

347. Faraji S, Dreuw A (2012) J Phys Chem Lett 3:227

348. Faraji S, Groenhof G, Dreuw A (2013) J Phys Chem B 117:10071

349. Tachikawa H, Kawabata H (2008) J Phys Chem B 112:7315

350. Doorley GW, McGovern DA, George MW, Towrie M, Parker AW, Kelly JM, Quinn SJ (2009) Angew Chem Int Ed 48:123

351. de La Harpe K, Crespo-Hernández CE, Kohler B (2009) ChemPhysChem 10:1421

352. Miyahara T, Nakatsuji H, Sugiyama H (2013) J Phys Chem A 117:42

353. Wan C, Fiebig T, Kelley SO, Treadway CR, Barton JK, Zewail AH (1999) Proc Natl Acad Sci USA 96:6014

354. Kelley SO, Barton JK (1999) Science 283:375

355. Wan C, Fiebig T, Schiemann O, Barton JK, Zewail AH (2000) Proc Natl Acad Sci USA 97:14052

356. Tamulis A, Tamulis V, Graja A (2006) J Nanosci Nanotech 6:965

357. McCullagh M, Franco I, Ratner MA, Schatz GC (2011) J Am Chem Soc 133:3452

358. McCullagh M, Franco I, Ratner MA, Schatz GC (2012) J Phys Chem Lett 3:689 